Louisiana State University

LSU Digital Commons

Faculty Publications

Department of Chemistry

5-13-2009

\title{
The structure of the cornified claw sheath in the domesticated cat (Felis catus): Implications for the claw-shedding mechanism and the evolution of cornified digital end organs
}

\author{
Dominique G. Homberger \\ School of Veterinary Medicine \\ Kyungmin Ham \\ School of Veterinary Medicine \\ Tolulope Ogunbakin \\ School of Veterinary Medicine \\ Jonathan A. Bonin \\ School of Veterinary Medicine \\ Brooke A. Hopkins \\ School of Veterinary Medicine
}

See next page for additional authors

Follow this and additional works at: https://digitalcommons.Isu.edu/chemistry_pubs

\section{Recommended Citation}

Homberger, D., Ham, K., Ogunbakin, T., Bonin, J., Hopkins, B., Osborn, M., Hossain, I., Barnett, H., Matthews, K., Butler, L., \& Bragulla, H. (2009). The structure of the cornified claw sheath in the domesticated cat (Felis catus): Implications for the claw-shedding mechanism and the evolution of cornified digital end organs. Journal of Anatomy, 214 (4), 620-643. https://doi.org/10.1111/j.1469-7580.2009.01068.x

This Conference Proceeding is brought to you for free and open access by the Department of Chemistry at LSU Digital Commons. It has been accepted for inclusion in Faculty Publications by an authorized administrator of LSU Digital Commons. For more information, please contact ir@lsu.edu. 


\section{Authors}

Dominique G. Homberger, Kyungmin Ham, Tolulope Ogunbakin, Jonathan A. Bonin, Brooke A. Hopkins, Michelle L. Osborn, Imtiaz Hossain, Heath A. Barnett, Kenneth L. Matthews, Leslie G. Butler, and Hermann H. Bragulla 


\title{
The structure of the cornified claw sheath in the domesticated cat (Felis catus): implications for the claw-shedding mechanism and the evolution of cornified digital end organs
}

Dominique G. Homberger, ${ }^{1}$ Kyungmin Ham, ${ }^{2}$ Tolulope Ogunbakin, ${ }^{3}$ Jonathan A. Bonin, ${ }^{1}$ Brooke A. Hopkins, ${ }^{1}$ Michelle L. Osborn, ${ }^{1}$ Imtiaz Hossain, ${ }^{4}$ Heath A. Barnett, ${ }^{3}$ Kenneth L. Matthews II, ${ }^{5}$ Leslie G. Butler ${ }^{3}$ and Hermann H. Bragulla ${ }^{6}$

${ }^{1}$ Department of Biological Sciences, ${ }^{2}$ Center for Advanced Microstructures and Devices, ${ }^{3}$ Department of Chemistry,

${ }^{4}$ Tier 1 Visualization Services Center, Information Technology Services, ${ }^{5}$ Department of Physics \& Astronomy, and

${ }^{6}$ Department of Comparative Biomedical Sciences, School of Veterinary Medicine, Louisiana State University, Baton Rouge, LA, USA

\begin{abstract}
The morphology of cornified structures is notoriously difficult to analyse because of the extreme range of hardness of their component tissues. Hence, a correlative approach using light microscopy, scanning electron microscopy, three-dimensional reconstructions based on x-ray computed tomography data, and graphic modeling was applied to study the morphology of the cornified claw sheath of the domesticated cat as a model for cornified digital end organs. The highly complex architecture of the cornified claw sheath is generated by the living epidermis that is supported by the dermis and distal phalanx. The latter is characterized by an ossified unguicular hood, which overhangs the bony articular base and unguicular process of the distal phalanx and creates an unguicular recess. The dermis covers the complex surface of the bony distal phalanx but also creates special structures, such as a dorsal dermal papilla that points distally and a curved ledge on the medial and lateral sides of the unguicular process. The hard-cornified external coronary horn and proximal cone horn form the root of the cornified claw sheath within the unguicular recess, which is deeper on the dorsal side than on the medial and lateral sides. As a consequence, their rate of horn production is greater dorsally, which contributes to the overall palmo-apical curvature of the cornified claw sheath. The external coronary and proximal cone horn is worn down through normal use as it is pushed apically. The hard-cornified apical cone horn is generated by the living epidermis enveloping the base and free part of the dorsal dermal papilla. It forms nested horn cones that eventually form the core of the hardened tip of the cornified claw. The sides of the cornified claw sheath are formed by the newly described hardcornified blade horn, which originates from the living epidermis located on the slanted face of the curved ledge. As the blade horn is moved apically, it entrains and integrates the hard-cornified parietal horn on its internal side. It is covered by the external coronary and proximal cone horn on its external side. The soft-cornified terminal horn extends distally from the parietal horn and covers the dermal claw bed the tip of the uniguicular process, thereby filling the space created by the converging apical cone and blade horn. The soft-cornified sole horn fills the space between the cutting edges of blade horn on the palmar side of the cornified claw sheath. The superficial soft-cornified perioplic horn is produced on the internal side of the unguicular pleat, which surrounds the root of the cornified claw sheath. The shedding of apical horn caps is made possible by the appearance of microcracks in the superficial layers of the external coronary and proximal cone horn in the course of deformations of the cornified claw sheath, which is subjected to tensile forces during climbing or prey
\end{abstract}

Correspondence

Dr Dominique G. Homberger, Department of Biological Sciences, 202 Life Sciences Building, Louisiana State University, Baton Rouge, LA 70803-1715, USA.E: zodhomb@lsu.edu

Accepted for publication 30 January 2009 
catching. These microcracks propagate tangentially through the coronary horn and do not injure the underlying living epidermal and dermal tissues. This built-in shedding mechanism maintains sharp claw tips and ensures the freeing of the claws from the substrate.

Key words cat; claw; claw-shedding mechanism; cornified digital end organ; dermo-epidermal interface.

\section{Introduction}

Cornified end organs are characteristic of terrestrial tetrapods and, in particular, of mammals. Traditionally, they have been conceptualized as consisting of wall horn and sole horn (e.g. Boas, 1931; Starck, 1982), and this basic subdivision has been widely used to establish homologies among the hooves, nails and claws of mammals (e.g. Hamrick, 2001). Cornified end organs have also been studied from a medical point of view and, as a result, the greatest attention, by far, has been lavished on the morphology and development of the horse hoof and the human finger nail. Claws have generally garnered less interest, although they have been studied within an eco-morphological context (e.g. Hamrick, 2003).

Sharp claws that are retracted within protective skin folds when not in use for climbing or for catching prey are characteristic of the members of the cat family Felidae (except the cheetah, Acinonyx jubatus). Although the structures responsible for the retraction mechanism of the distal phalanx in cats have been studied extensively (Siedamgrotzky, 1871; Gonyea \& Ashworth, 1975; Bryant et al. 1996), the structure of the cornified claw sheath itself has only rarely been analysed (see Siedamgrotzky, 1871; Ernsberger, 1998). The microstructures that underlie the mechanisms whereby cats maintain their cornified claws sharp and in good functioning order have been studied even less.

That a superficial layer of the cornified claw sheath is shed when domesticated cats appear to sharpen their claws by scratching rough surfaces, such as tree bark or rough textiles, is well known among pet owners and veterinarians, and was mentioned earlier by De Weerdt (1927). Siedamgrotzky (1871), though, described a continuous abrasion as the mechanism for keeping claws sharp and seems to have been unaware that cats shed horn caps off their claws. Interestingly, in Dyce et al. (2002), a shed horn cap of a cornified claw sheath is shown as an example of an actual cat claw. However, the internal architecture of the cornified material that allows such a controlled shedding of its superficial layer without cracks propagating into the underlying living tissues has not been analysed and cannot be inferred from the currently available information on the morphology of claws. Not only domesticated cats but also large cats, such as lions, tigers and bobcats (staff at the Baton Rouge Zoo, personal communication), small dogs (Barbara Luikhart, Galvez Veterinary Clinic, Prairieville, Louisiana, personal communication), and even horses (K.-D. Budras, Institute of Veterinary Anatomy, Free University Berlin, unpublished observation of a Przewalski horse) can shed their claws or hooves. Hence, the phenomenon of shedding superficial parts of cornified digital end organs is of a more general interest and warrants a better understanding of the morphology of cornified end organs to explain the mechanisms that are involved.

Our analysis of the morphology of the cornified claw sheath of domesticated cats was originally conceived as a preliminary study using easily obtainable specimens, which would prepare the ground for a better understanding of the structure and internal architecture of the rhamphotheca of the curved beaks of parrots (see Homberger, 2001). As the present study progressed, it was realized, however, that the claw of cats differs in fundamental ways from a bird beak and that the reason for these differences lay in the different local mechanical forces and functions of the individual horn elements within the context of an integrated cornified end organ. By the end of the study, it had become clear that a fundamental reconceptualization of the morphology of cornified end organs was needed in order to understand their functions, biological roles and evolutionary history.

In the present study, the structure of the cornified claw sheath is described and analysed as a basis for future comparisons with claws from other mammals and vertebrates (e.g. birds and reptiles). Such a comparison may eventually allow a reconstruction of the evolutionary history of claws from the earliest stage as seen in amphibians (see Maddin et al. 2009). The cornified claw sheath deserves to be described first and by itself because it is the part of the claw that interacts directly with the environment and is, therefore, directly exposed to the selective regime of physical forces. The anchoring of the cornified claw sheath to the underlying distal phalanx and its structural connections with the underlying dermis, which are responsible for the dermo-epidermal metabolic exchanges, will be examined in future studies.

\section{Materials and methods}

\section{Materials}

Specimens of domesticated cats were collected from local pounds and euthanized under an IACUC protocol (no. 04-057) for the humane treatment of animals supervised and granted by the Division of Laboratory Animal Medicine at the School of Veterinary Medicine, Louisiana State University.

In order to control the number of variables, whenever possible, only the fifth claw of the front paw was used to establish the basic structure of the cat claw. Future analyses will assess the variability of all claws within and between the front and hind paws. 
Table 1 Specimens and imaging techniques used

\begin{tabular}{|c|c|}
\hline Specimen & Figure reference and imaging techniques \\
\hline $\begin{array}{l}\text { Cat no. } 50 \text { (tricolored adult female, fresh fifth } \\
\text { digit of left forepaw) }\end{array}$ & $\begin{array}{l}\text { Fig. } 1 \text { (digital photography through a stereomicroscope); Fig. 2a,b (digital } \\
\text { photography through a stereomicroscope); Fig. } 2 c-f \text { (virtual three-dimensional } \\
\text { imaging from x-ray computed tomography data) }\end{array}$ \\
\hline $\begin{array}{l}\text { Cat no. } 1 \text { (adult male, third digit of right } \\
\text { forepaw) }\end{array}$ & $\begin{array}{l}\text { Fig. 3a-c (vascular injection of fresh specimen with contrast agent, embedding of the } \\
\text { subsequently fixed specimen in resin, and mesoscopic sectioning) }\end{array}$ \\
\hline $\begin{array}{l}\text { Cat } \mathrm{G} \text { (10 days old, third or fourth digit of } \\
\text { a forepaw) }\end{array}$ & $\begin{array}{l}\text { Fig. } 4 \text { (digital photography through an optical compound microscope of stained } \\
\text { histological sections) }\end{array}$ \\
\hline $\begin{array}{l}\text { Cat no. } 21 \text { (male, older than } 22-24 \text { months; } \\
\text { fifth digit of left forepaw) }\end{array}$ & Figs 5, 6b, 7b (scanning electron microscopy) \\
\hline $\begin{array}{l}\text { Cat no. } 18 \text { (adult female, fifth digit of right } \\
\text { forepaw) }\end{array}$ & Figs 6, 7 (scanning electron microscopy) \\
\hline $\begin{array}{l}\text { Cat no. } 24 \text { (Persian adult male, fifth digit of } \\
\text { left forepaw) }\end{array}$ & $\begin{array}{l}\text { Fig. } 8 \text { (digital photography through a stereomicroscope); Fig. } 9 \text { (virtual } \\
\text { three-dimensional imaging from x-ray computed tomography data); Fig. 12a,b,e,g,i } \\
\text { (virtual three-dimensional imaging of computed volumes from x-ray computed } \\
\text { tomography data) }\end{array}$ \\
\hline $\begin{array}{l}\text { Cat no. } 45 R \text { (spayed adult female, fifth digit } \\
\text { of right forepaw) }\end{array}$ & $\begin{array}{l}\text { Fig. } 10 \text { (digital photography through a stereomicroscope); Fig. } 11 \text { (virtual } \\
\text { three-dimensional imaging from x-ray computed tomography data); Fig. 12c,d,f,h,j } \\
\text { (virtual three-dimensional imaging of computed volumes from x-ray computed } \\
\text { tomography data) }\end{array}$ \\
\hline & Fig. 13 (virtual three-dimensional imaging from x-ray computed tomography data) \\
\hline
\end{tabular}
forepaw)

SC no. 3 (adult female, shed cornified claw sheath)

SC no. 5 (adult female, shed cornified claw sheath)

Fig. 14a (scanning electron microscopy)

Fig. 14b (scanning electron microscopy)

\section{Preparation techniques}

Cornified epidermal structures (e.g. claws and beaks) are notoriously difficult to analyse morphologically because of the extreme range of hardness of their component tissues in adult specimens. As each analytical technique is characterized by intrinsic artifacts, a variety of techniques were applied to gain an integrated understanding of the morphology through a composite of data. Whenever possible, more than one technique was applied to the same specimen to test the degree of accuracy and realism of the created images (Table 1).

Fresh specimens from adult cats were immediately frozen and stored at $-20{ }^{\circ} \mathrm{C}$. To retain lifelike conditions as much as possible, they were subjected to imaging procedures, whenever possible and appropriate, without prior preservation and were exposed to room temperature as briefly as possible in order to minimize drying and shrinkage. If the specimens were preserved, they were fixed in $4 \%$ formalin and stored in 1-2\% phenoxyethanol.

To distinguish the vascularized dermis and bone from the avascular epidermis, the vascular system of unpreserved adult cats was injected with $100 \% \mathrm{BaSO}_{4}\left(100 \%\right.$ Esophotrast ${ }_{0}$; Barnes-Hind Diagnostics, Canovanas, Puerto Rico) as a contrast agent. The specimens were subsequently preserved in $4 \%$ formalin and stored in $1-2 \%$ phenoxyethanol.

To show the integrated configuration of structures in situ, mesoscopic sections were prepared from intact claws of adult cats after embedding them in liquid resin (Batson's no. 17; Polysciences Inc., Warrington, PA, USA) and sectioning them with an oscillating compass saw after the resin had hardened.

To show the integrated configuration of tissues in situ, histological sections were prepared from intact claws of 10-day-old kittens by embedding the specimens in paraffin, sectioning the embedded specimens with a microtome, and staining the processed sections with hematoxylin-eosin.

To show the configuration of the skeletal framework that supports the dermis, the bony elements of claws were physically isolated through bacterial maceration in water at room temperature $\left(19-21^{\circ} \mathrm{C}\right)$ for about 4 weeks.

To reveal the three-dimensional configuration and internal architecture of the epidermal tissues and the three-dimensional configuration of the interfaces between the living and cornified layers of the epidermis and between the epidermis and dermis (see 'Imaging methods' below), the various epidermal parts of claws were physically isolated through two different maceration techniques. Bacterial maceration in water at room temperature prior to preservation retained only the hard-cornified epithelial tissue. Chemical maceration in 1\% acetic acid for 7-10 days at room temperature retained the soft- and hard-cornified horn as well as the living epidermal layers by separating the epidermis in toto from the dermis.

To reveal the detailed surface structure of the epidermis and bony elements, specimens were prepared for scanning electron microscopy (SEM) by dehydrating them in a graded series of ethanol and in hydroxymethyldisilazane (SPI-Chem, West Chester, PA, USA). The dried specimens were mounted on aluminum stubs with an electrical current-conducting glue (Leit-C, SPI-Chem) and sputter-coated with gold for 3 minutes to achieve an $80 \mathrm{~nm}$ thick layer of gold.

As an alternative to trying to prepare SEM pictures of the soft tissues that underlie the cornified claw sheath to show their three-dimensional configuration and contours, images of virtual casts of the volumes enclosed by physically isolated epidermal 
tissues (i.e. cornified claw sheaths with or without their associated living epidermal layers) were reconstructed from x-ray computed tomography data. This technique (see 'Imaging methods' below) was necessary because the dermis (after separation from the epidermis through acetic acid) would dry, shrivel and become distorted during processing for SEM.

\section{Imaging methods}

Mesoscopic digital photographs were prepared with a stereo microscope (Leica MZ6) with a digital camera attachment (Spot Insight Firewire, Diagnostic Instruments, Inc., Sterling Heights, MI, USA), extended focus computer software (Image-Pro Plus 5.1 and In-Focus 1.60), and ring-light and gooseneck fiber-optics, which were equipped with polarizing filters and connected to a light box (Intralux 6000, Volpi USA, Auburn, NY, USA). Fresh and preserved specimens, as well as mesoscopic sections, were imaged by this method to show individual structures within the context of entire claws.

Optical microscopy pictures were prepared from stained histological sections using a digital camera (ProgRes 3012; Zeiss, Ober-Cochem, Germany) attached to an optical microscope (Axioscope, Zeiss). These pictures show the nature and topographical relationships of the various tissues of the claws.

The SEM images were prepared using a scanning electron microscope (Quanta 200; FEI-Philips, Eindhoven, The Netherlands) from adult specimens to show the configuration of surfaces or interfaces. The interfaces between two different tissues were made visible by special preparation techniques (see 'Preparation techniques' above).

Graphic models were prepared from individual images by using the software Photoshop 9, CS2 or CS3 (Adobe, San Jose, CA, USA) to show the structural and topographical relationships of particular tissues and structures.

Color-coded images were prepared from individual images by using the software Photoshop 9, CS2 or CS3 to show the location and extent of particular regions within a structure.

Virtual three-dimensional images were prepared from x-ray computed tomography data collected from fresh, intact adult specimens or from physically isolated cornified claw sheaths with a SkyScan 1074 tomography imaging system (Micro Photonics, Allentown, PA, USA) (40 kVp polychromatic x-ray beam; field of view of $28 \mathrm{~mm}$ in diameter and $19 \mathrm{~mm}$ in height; voxel side length $37 \mu \mathrm{m}$ ) and visualized with the software Avizo 5 (Mercury Computer Systems, Berlin, Germany). Physical isolation of particular tissue types (see above) prior to scanning is an alternative to manual segmentation of individual tissue types from x-ray computed tomography data of whole organs.

Other virtual three-dimensional images were prepared from phasecontrast enhanced synchrotron x-ray computed tomography data collected from preserved adult specimens at the Advanced Photon Source (Argonne National Laboratory, University of Chicago, Chicago, IL, USA) (20 keV monochromatic x-ray beam; field of view of $7.19 \mathrm{~mm}$ in diameter and $5.7 \mathrm{~mm}$ in height; scintillator distance to specimen $330 \mathrm{~mm}$; voxel side length $11.06 \mu \mathrm{m}$ ) (see also Ham et al. 2006) and visualized through manual segmentation using the software Amira 4 (Mercury Computer Systems).

As an alternative to trying to prepare SEM pictures of the soft tissues (see above), images of virtual casts of the volumes enclosed by physically isolated epidermal tissues (i.e. cornified claw sheaths with or without their associated living epidermal layers and softcornified horn segments) were reconstructed from x-ray computed tomography data collected with a SkyScan 1074 tomography imaging system (Micro Photonics, Allentown, PA, USA) (40 kVp x-ray beam; field of view of $28 \mathrm{~mm}$ in diameter and $19 \mathrm{~mm}$ in height; voxel side length $37 \mu \mathrm{m})$. Because the cornified claw sheath frames but does not enclose the soft tissues (e.g. Fig. 11b,c), it was not possible to obtain a virtual cast of the soft tissues with the currently existing commercial visualization package Avizo 5 (Mercury Computer Systems); hence, there was a need for external processing using Matlab 7 (The Mathworks, Inc., Natick, MA, USA). The x-ray computed tomography data were loaded into Avizo 5, and the CalculusMatlab module was used to pass the data into a Matlab session. An algorithm was developed and implemented in Matlab, which computed a mask for the inner empty space that is framed but not enclosed by the cornified claw sheath. The algorithm follows a constrained flood fill approach on individual slices of the aligned dataset. The virtual cast was then passed back to the visualization space in Avizo 5 for comparison and analysis.

\section{Observations}

\section{External morphology of the claw and associated epidermal structures}

The claws of a cat are retroflexed (i.e. hyperextended) in their resting position and held off the ground during locomotion. In this position, the claw portion that is covered by the cornified claw sheath is almost completely retracted into a protective skin pouch, and its protruding tip is covered by the long hairs of the fur that covers the folds of the skin pouch (Figs 1, 2, 3a,b). The lateral side of the fifth claw is completely covered by the lateral fold of the skin pouch but, on the medial side, the medial fold of the skin pouch merges with the skin fold between the fifth and fourth digits (Figs 1c, 2a). The fold of the skin pouch does not cross the palmar (sole) side of the claw (Fig. 1a,b). The internal sheet of the fold of the skin pouch is anchored to the cornified claw sheath along the proximal base of the unguicular pleat (Fig. 3a,b). When the claw is protracted by flexing the distal interphalangeal joint, the folds of the skin pouch are stretched, thereby exposing the cornified claw to various degrees and even the unguicular pleat (see below), depending on the degree of flexion of the distal interphalangeal joint (Fig. 1).

The unguicular pleat is formed by a cutaneous fold but, unlike the fold of the skin pouch, it cannot be stretched and flattened out as it is anchored to the distal rim of the unguicular hood (Figs 3a,b, 4a,c). The epidermis of the internal sheet of the unguicular pleat, which faces the surface of the cornified claw sheath, generates perioplic horn and, thus, is called the perioplic epidermis (Figs 3a, 4a-c). The unguicular pleat forms a tight band around the base of the wall horn (Table 2) and continues as the so-called skin fold connecting the palmar flanges of coronary horn of the cornified claw sheath (Figs 3a, 4a-c). This skin fold does not adhere to the horn surface and forms a recess that is filled with sole horn, which is generated by the sole epidermis of the cornified claw sheath (see below). 


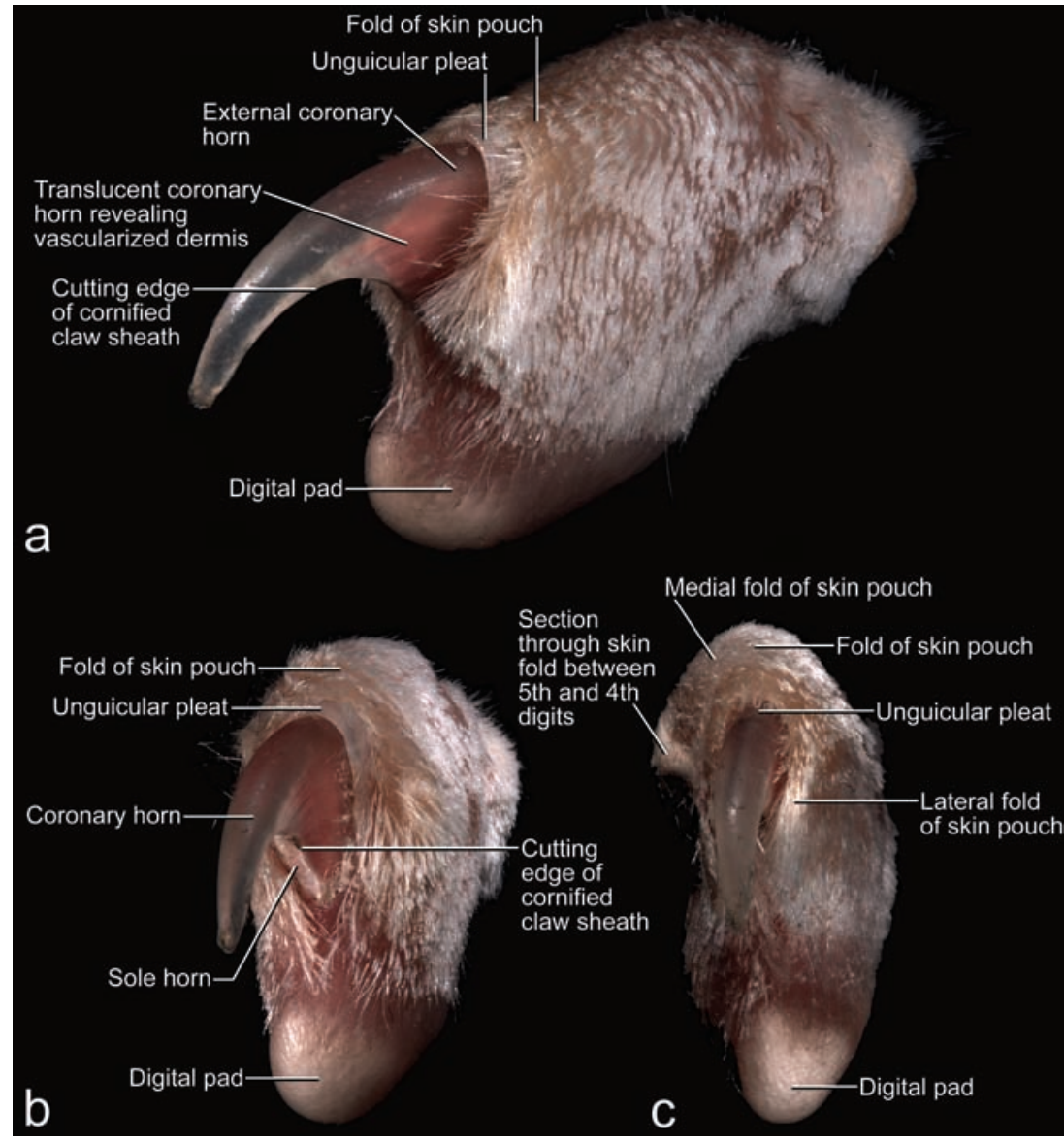

Fig. 1 Mesoscopic digital photographs of the unpreserved fifth digit in resting position with a maximally retracted (i.e. retroflexed or hyperextended) claw of a cat (cat no. 50, tricolored adult female, left forepaw) to show the configuration of the skin pouch and unguicular pleat in situ. The fold of the skin pouch was slightly pulled back to reveal the underlying unguicular pleat. The long hairs of the furry skin fold originally covered most of the claw; they were clipped with microscissors. (a) Dorsolateral view. (b) Distolateral view. (c) Distal view.
At the macroscopic level, the cornified claw sheath appears to consist of two parts, i.e. the hard, shiny wall horn and the friable, dull sole horn (Fig. 1), which corresponds to the traditional classification of the horn material of cornified digital end organs in reptiles, birds and mammals (e.g. Boas, 1931; Starck, 1982), although a closer look at the internal structure of the cornified claw sheath reveals a more complex architecture (Table 2).

\section{Skeletal elements of the claw}

In adult cats, the distal phalanx consists of a proximal articular base for the articulation with the middle phalanx and for the attachment of tendons and ligaments, a distal unguicular process supporting the cornified claw sheath, and an ossified unguicular hood (Figs $2 c-f, 3,4,5$ ). The articular base comprises the extensor process to which the tendon of the $M$. extensor digitorum communis inserts and the flexor tubercle to which the tendon of the $M$. flexor digitorum profundus inserts (Figs 3a, 4a,c, 5a,b). The ossified unguicular hood is anchored to the articular base and cups the proximal part of the unguicular process, thereby creating a deep unguicular recess, which accommodates the root of the cornified claw sheath (Figs 6, 7b).
The developing distal phalanx has only one growth plate between the articular base and the unguicular process (Fig. 4a,c). The articular base ossifies through endochondral indirect (i.e. cartilage replacement) ossification and the unguicular process ossifies through perichondral and endochondral indirect ossification. The unguicular hood remains fibrous until the age of 5-6 months, starts to ossify at about 6 months of age through direct (desmal or membranous) ossification, and is completely ossified between the ages of 12 and 24 months (Bragulla \& Homberger, unpublished observations).

\section{Dermal connective tissue of the claw}

The vascularized and innervated dermis mechanically and metabolically supports the avascular living epidermis of the cornified claw sheath. It also anchors the cornified claw sheath to the bony tissue of the terminal phalanx. The thickness of the dermis varies; as a result, the threedimensional profiles of the dermis and distal phalanx differ (Figs 3b, 4, 5). In particular, the dermis forms a distinct dorsal dermal papilla that points distally and is anchored to the distal surface of the extensor process of the articular base of the distal phalanx. Near its base, the dorsal dermal 
Fig. 2 Images of the unpreserved fifth digit in resting position with a maximally retracted (i.e. retroflexed or hyperextended) claw of a cat (cat no. 50, tricolored adult female, left forepaw) to show the surface structures as well as the internal configuration of the cornified claw sheath and skeletal elements in situ. (a and b) Mesoscopic digital photographs. (a) Medial view. (b) Lateral view. (c-f) Images based on three-

dimensional visualization of $\mathrm{x}$-ray computed tomography data (40 kVp x-ray beam; field of view of $28 \mathrm{~mm}$ in diameter and $19 \mathrm{~mm}$ in height; voxel side length $37 \mu \mathrm{m})$. Red: Density of hard-cornified epidermis, as well as transitional tissue density between blue and green. Green: Density of bone. Blue: Density of soft tissue (living and soft-cornified epidermis, and dermis). (c and d) Soft tissues shown slightly transparent. (c) Medial view. (d) Lateral view. (e and f) Only bone and hardcornified epidermis shown. (e) Medial view. (f) Lateral view. $A B$, articular base of distal phalanx; CCS, cornified claw sheath; DP, digital pad; FSP, fold of skin pouch; LSP, lateral fold of skin pouch; MP, middle phalanx; MSP, medial fold of skin pouch; $S B D$, section through the skin fold between the fifth and fourth digits; UH, unguicular hood of distal phalanx; UP, unguicular process of distal phalanx.

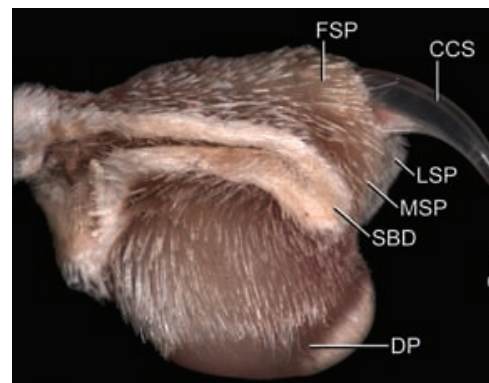

a

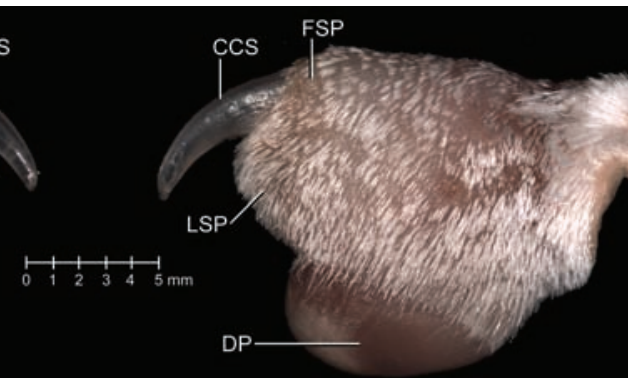

b

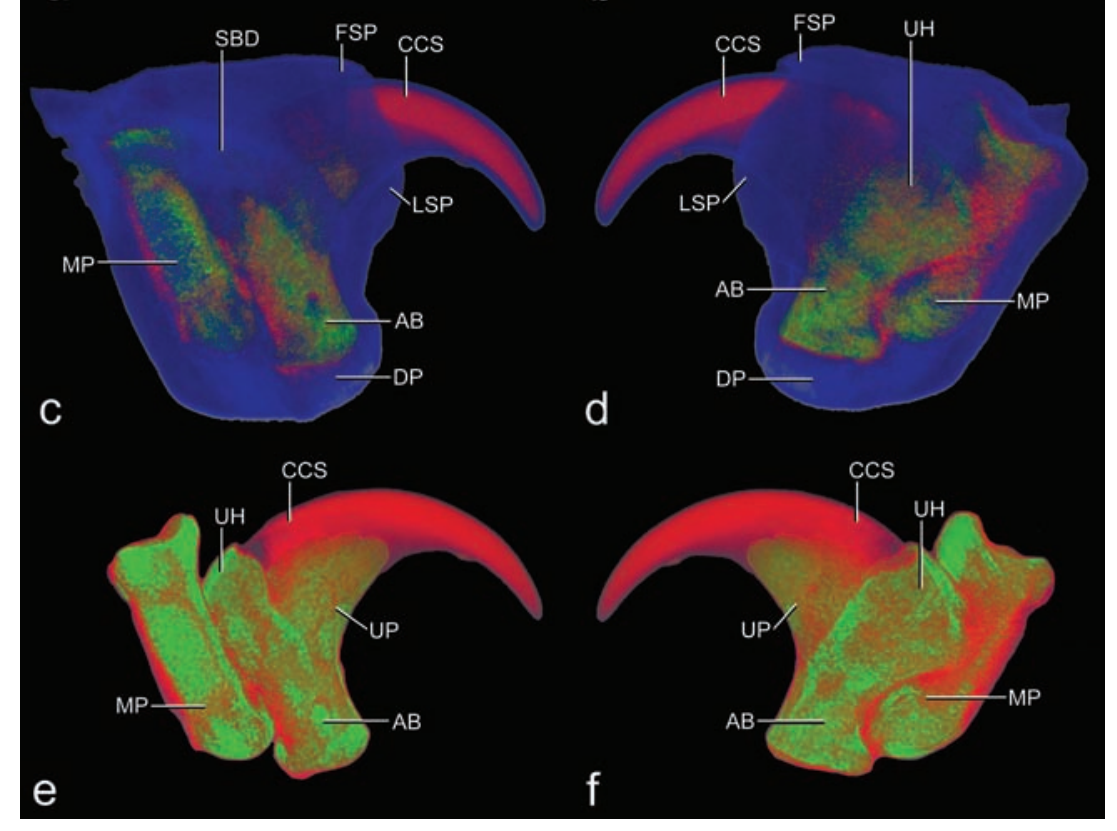

papilla is tethered by a dermal frenulum to the dermis along the dorsal ridge of the bony unguicular process (Fig. 4), thereby creating a longitudinal trough between the dorsal dermal papilla and the dermis covering the sides of the unguicular process (i.e. dermal claw bed) (Fig. 4b). This trough continues palmo-proximally into a curved ledge that is created by the thickened proximal extension of the dorsal dermal papilla all the way to the bottom of the unguicular recess (Figs $7,8 b, c, 9 b$ ). The face of the curved ledge is slanted (Figs 7a, 9f).

The dermis is supplied by a variety of blood vessels that pass through the numerous foramina of the distal phalanx (Fig. 5; Bragulla \& Homberger, unpublished observations). The dermal areas are identified here by their relationship to the epidermal segments as a way to correlate the topography of the bone with that of the epidermis (see also Table 2). The dermis that supports the living epidermis of the proximal cone horn (see below) within the unguicular recess is supplied by the blood vessels that pass through the dorsal and palmar vascular foramina of the unguicular hood. These blood vessels are the only supply channels for the proximal cone epidermis because the underlying bone surface is devoid of foramina nutricia.
The dermis that supports the living epidermis of the external coronary horn (see below) is supplied by blood vessels that pass through the minor vascular foramina on the internal side of the unguicular hood. The dermis covering the unguicular process is supplied by two vascular sources. The major blood vessels passing through the vascular foramen of the unguicular process continue through the medullary cavity of the unguicular process as medullary blood vessels (Fig. 3a). These blood vessels send and receive vascular branches that run through parallel longitudinal bone canals within the unguicular process and emerge distally through minor vascular foramina to supply the dermis that supports the parietal, crest, apical cone, terminal and sole horn (see below). Vascular branches of the blood vessels that pass through the palmar vascular foramen of the unguicular hood follow the parietal vascular groove of the unguicular process and connect with branches of the medullary blood vessels through connecting vascular foramina within the parietal vascular groove. The parietal vascular grooves on the surface of the lateral and medial sides of the unguicular process parallel the bony canals that lodge the medullary blood vessels (compare Figs $3 a, 5)$. 


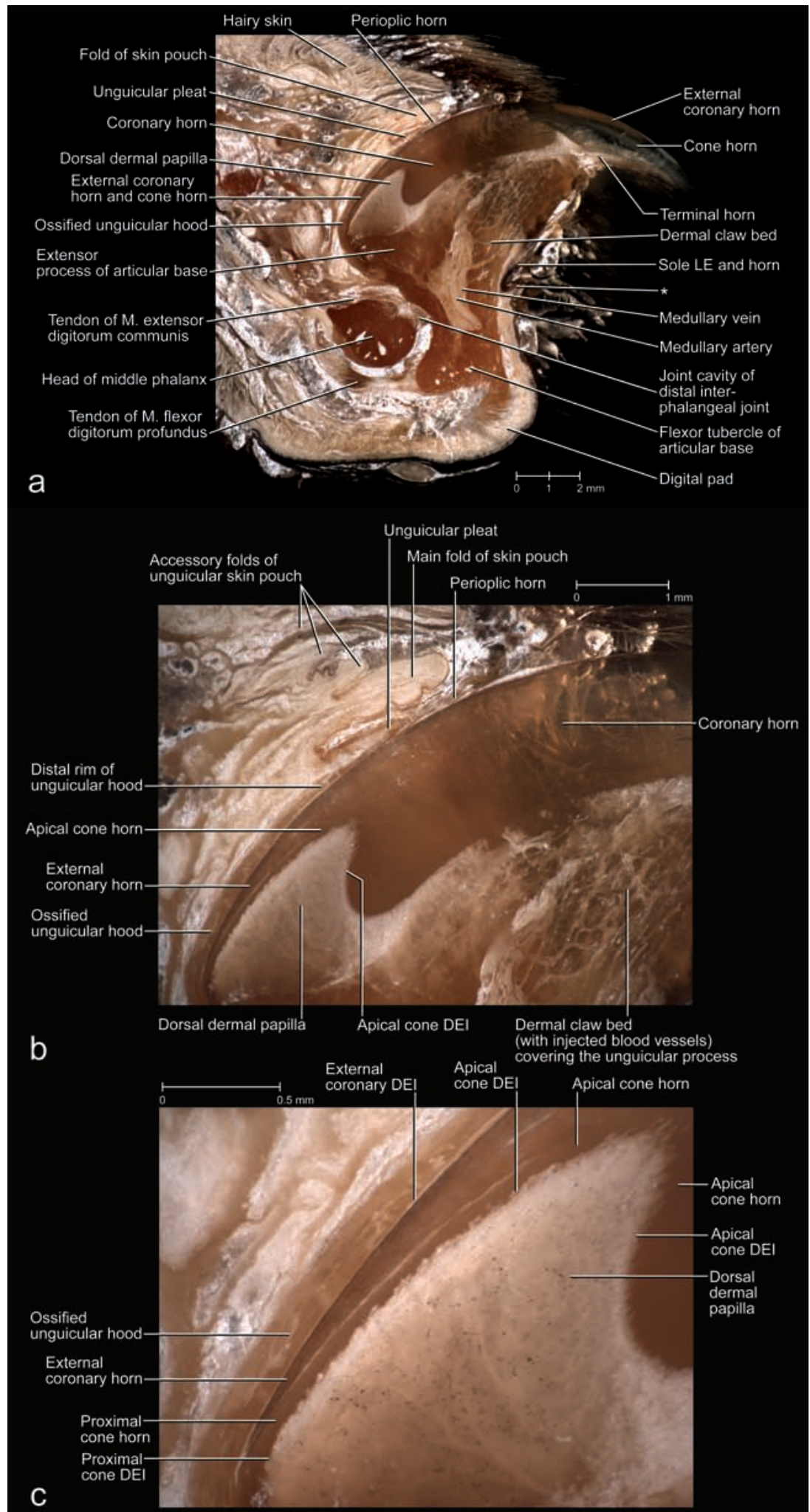

Fig. 3 Mesoscopic digital photographs of lateral views of a slightly oblique paramedian section through the third digit with a retracted claw of a cat (cat no. 1, adult male, right forepaw). The vascular system was injected with white $100 \% \mathrm{BaSO}_{4}$ to distinguish the vascularized dermis and bone from the avascular epidermis (some depressions and cavities were contaminated with $\mathrm{BaSO}_{4}$ ). The specimen was embedded in resin prior to sectioning. (a) Section through the entire digit to show the complex relationships among the various structural elements supporting the cornified claw sheath. Part of the coronary horn at the tip of the claw was broken off during the sectioning process, thereby revealing the underlying core of the tip of the cornified claw sheath.

(b) Magnified section to show the relationships among the bony unguicular hood, unguicular pleat, unguicular skin fold, and cornified claw sheath. (c) Magnified section to show the relationships between the external coronary horn and proximal cone horn. Note the small dermal papillae of the cone dermo-epidermal interface (DEI) and the injected blood vessels within the ossified unguicular hood and dorsal dermal papilla. The white longitudinal lines within the coronary horn are microcracks that have become contaminated with $\mathrm{BaSO}_{4}$ during the sectioning process. $L E$, living epidermis; *, skin fold connecting the palmar flanges of coronary horn.

\section{Epidermal components of the cornified claw sheath}

The cornified claw sheath is generated by the living avascular epidermis, which is mechanically and metabolically supported by the underlying dermis. Traditionally, it has been subdivided into wall horn and sole horn (e.g. Siedamgrotzky, 1871; Boas, 1931; Starck, 1982; Dyce et al. 2002), but it can be further subdivided into horn segments that 

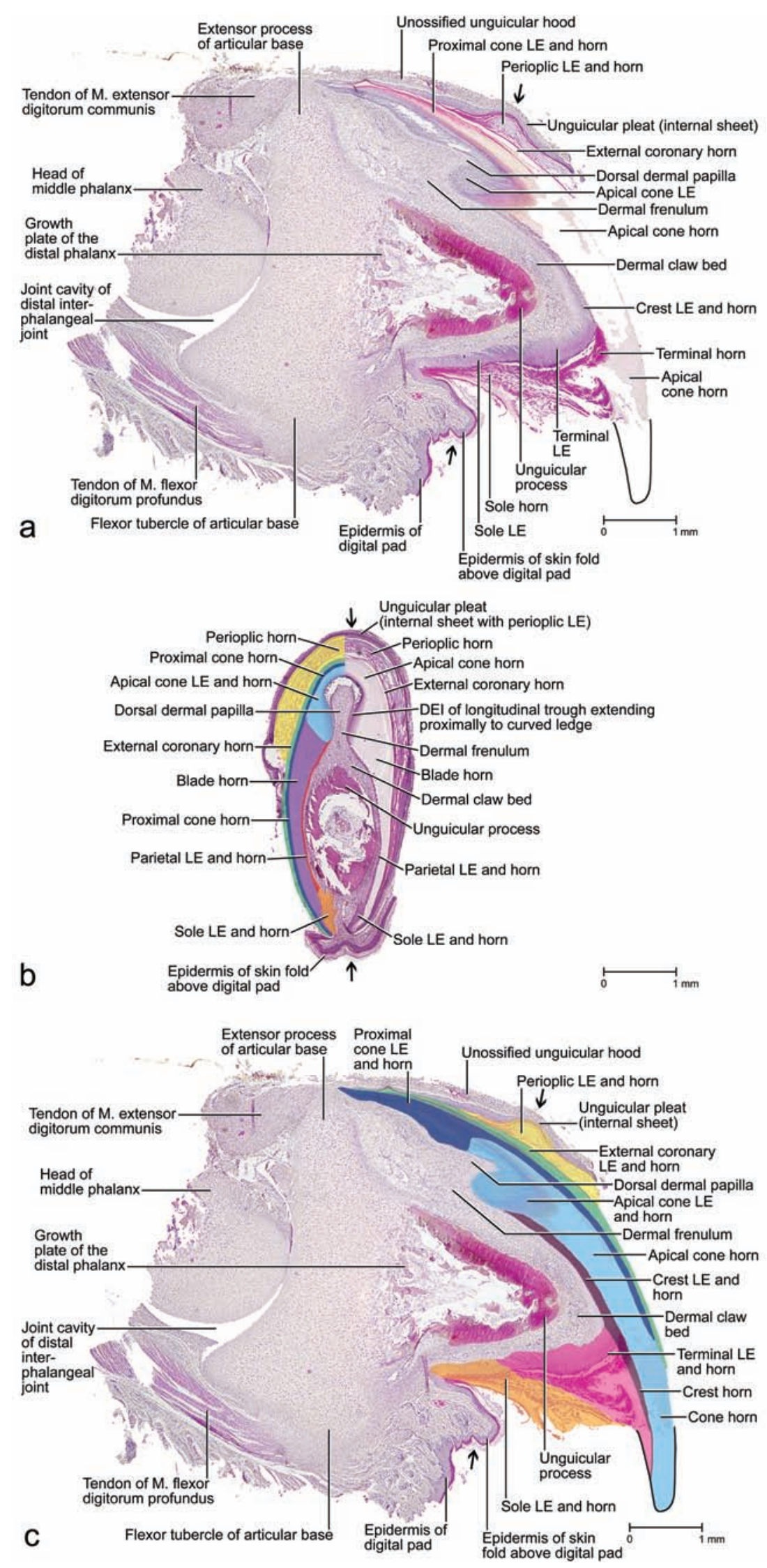

Fig. 4 Microscopy images of stained histological sections of claws of a kitten (cat $\mathrm{G}, 10$ days old, third or fourth digit of a forepaw) to show the tissue composition in situ. At this stage of development, only the unguicular process of the distal phalanx is ossifying, while the articular base is still cartilaginous and the unguicular hood is still fibrous. (a) Paramedian section at the level indicated by a pair of opposite arrows in (b); much of the apical part of the cone horn was torn away during the sectioning process due to its extreme hardness. (b) Transverse section at the level indicated by the pair of opposite arrows in (a); the epidermal elements of the cornified claw sheath are color-coded on the left half of the section. (c) Paramedian section at the level indicated by a pair of opposite arrows in (b); the epidermal elements of the cornified claw sheath are color-coded. DEI, dermo-epidermal interface; LE, living epidermis; M., Musculus.
(C) 2009 The Authors

Journal compilation (C) 2009 Anatomical Society of Great Britain and Ireland 
The cornified claw sheath of the cat, D. G. Homberger et al.

Table 2 Horn divisions of the cornified claw sheath of adult domesticated cats

\begin{tabular}{|c|c|c|c|c|c|c|c|}
\hline \multicolumn{5}{|c|}{ Horn divisions and segments } & $\begin{array}{l}\text { Location of the horn- } \\
\text { generating epidermis }\end{array}$ & $\begin{array}{l}\text { Location within the cornified } \\
\text { claw sheath }\end{array}$ & $\begin{array}{l}\text { Cornification } \\
\text { type }^{1}\end{array}$ \\
\hline \multirow{8}{*}{$\frac{5}{\frac{5}{c}}$} & \multicolumn{4}{|c|}{ Perioplic horn (Eponychium) } & $\begin{array}{l}\text { Dermis underlying the inner } \\
\text { sheet of the unguicular pleat } \\
\text { (Figs } 3,4 a, c, 6 \text { ) }\end{array}$ & $\begin{array}{l}\text { Underneath and along the apical } \\
\text { edge of the unguicular pleat } \\
\text { (Figs } 3 a, b, 4,6,7)\end{array}$ & Soft \\
\hline & \multirow{5}{*}{ 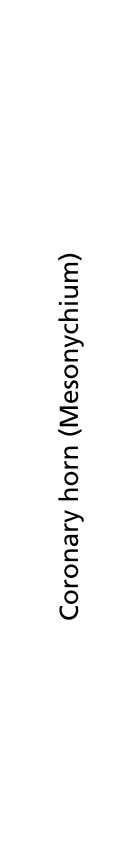 } & \multicolumn{3}{|c|}{ External coronary horn } & $\begin{array}{l}\text { Dermis lining the internal } \\
\text { surface of the ossified } \\
\text { unguicular hood (Figs } 3,4,6 \text {, } \\
7,8 a, b, 9 d \text { ) }\end{array}$ & $\begin{array}{l}\text { Surface of the cornified claw } \\
\text { sheath (Figs 1, 3, 4, 6, 7, 8a,b, } \\
9 b-f, 10 a, b, 11)\end{array}$ & Hard \\
\hline & & \multirow{4}{*}{ 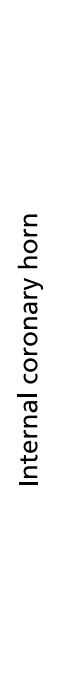 } & \multirow{2}{*}{ 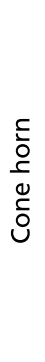 } & $\begin{array}{l}\text { Proximal } \\
\text { cone horn }\end{array}$ & $\begin{array}{l}\text { Dermis covering the bony } \\
\text { articular base proximo- } \\
\text { dorsally to the curved ledge } \\
\text { within the unguicular recess } \\
\text { (Figs } 3,4 a, c, 7,8 b, c, 9 b, c, e, f \text {, } \\
10 c, 11,12 \text { ) }\end{array}$ & $\begin{array}{l}\text { Underneath the external coronary } \\
\text { horn, as well as surrounding the } \\
\text { apical cone horn (Figs } 3,4,6,7 \text {, } \\
9 b, d-f, 11 \text { ) }\end{array}$ & \multirow[t]{2}{*}{ Hard } \\
\hline & & & & $\begin{array}{l}\text { Apical } \\
\text { cone horn }\end{array}$ & $\begin{array}{l}\text { Dermis covering the dorsal } \\
\text { dermal papilla (Figs } 3,4,7 \text {, } \\
9 b-d, 12 \text { ) }\end{array}$ & $\begin{array}{l}\text { The core and tip of the cornified } \\
\text { claw sheath through nested cones } \\
\text { of horn (Figs } 4 a, c, 6,7,9,11 \text {, } \\
13 a, b)\end{array}$ & \\
\hline & & & \multicolumn{2}{|c|}{ Crest horn } & $\begin{array}{l}\text { Apical edge of the dermal } \\
\text { frenulum and dermis along } \\
\text { the dorsal edge of the } \\
\text { unguicular process (Figs } 4 a, c \text {, } \\
9 b-d, f, 11 a, c, 12 \text { ) }\end{array}$ & $\begin{array}{l}\text { Midsagittal wedge on palmar side } \\
\text { of apical cone horn (Figs } 4 a, c, 7 \text {, } \\
8 b, c, 9 b, f, 10 c, 11 a, 13 a, b, 14)\end{array}$ & Hard \\
\hline & & & \multicolumn{2}{|c|}{ Blade horn } & $\begin{array}{l}\text { Dermis on the slanted face of } \\
\text { the curved ledge (Figs } 8 b, c \text {, } \\
9 b, c, f, 10 c, 11 a, c, 12,14 a \text { ) }\end{array}$ & $\begin{array}{l}\text { Sides of the cornified claw } \\
\text { sheath, palmo-proximal to the } \\
\text { cone horn, external to the parietal } \\
\text { horn (Figs } 4 b, 9 e, f, 13 a, b, 14 a \text { ) }\end{array}$ & Hard \\
\hline & \multirow{2}{*}{ 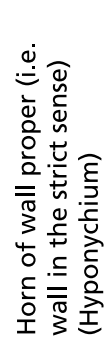 } & \multicolumn{3}{|c|}{ Parietal horn } & $\begin{array}{l}\text { Sides of the dermal frenulum } \\
\text { and dermis on the sides of } \\
\text { ossified unguicular process } \\
\text { (Figs } 4 b, 7,8 b, c, 9 b-d, f \text {, } \\
10 c, 11,12,13 a \text { ) }\end{array}$ & $\begin{array}{l}\text { Underlying the blade horn and } \\
\text { continuing apically into the } \\
\text { terminal horn (Figs } 4 b, 9 f, 13 a \text { ) }\end{array}$ & Hard \\
\hline & & \multicolumn{3}{|c|}{ Terminal horn } & $\begin{array}{l}\text { Dermis covering the tip of the } \\
\text { ossified unguicular process } \\
\text { (Figs } 3 a, 4 a, c, 7,11 a \text {, } \\
12 a, b, e, g, i, 13 a)\end{array}$ & $\begin{array}{l}\text { Space enclosed dorsally by the } \\
\text { cone horn, laterally by the blade } \\
\text { and parietal horn (Figs } 3 a, 4 a, c \\
7,8 b, c, 9 b-d, 12 c, d, f, h, j, 13 a, b \text {, } \\
\text { 14a) }\end{array}$ & Soft \\
\hline$\frac{5}{\frac{5}{c}}$ & \multicolumn{4}{|c|}{ Sole horn } & $\begin{array}{l}\text { Dermis on the palmar side of } \\
\text { the unguicular process } \\
\text { (Figs 3a, 4, 7, 9b-d, 12a,b, 13a) }\end{array}$ & $\begin{array}{l}\text { Space enclosed laterally by the } \\
\text { paired cutting edges of the } \\
\text { cornified claw sheath and apically } \\
\text { by the parietal and terminal horn } \\
\text { (Figs } 1 \mathrm{~b}, 3 \mathrm{a}, 4,7,8,9 \mathrm{~b}-\mathrm{f}, 12 \mathrm{c} \text {, d, } \\
\text { 13b) }\end{array}$ & Soft \\
\hline
\end{tabular}

${ }^{1}$ See also Bragulla \& Homberger (2007, 2009).

are characterized by their location within the cornified claw sheath, the location of the living epidermis generating them, their architecture and configuration and their mode of cornification (Table 2).

Traditionally, the epidermis of cornified end organs was assumed to contain hard keratin in contrast to the epidermis of the skin, which was assumed to contain soft keratin (see Homberger \& Brush, 1986; Homberger, 2001). Currently, however, our understanding of the processes involved in the keratinization and cornification of digital end organs has become much more differentiated (see Bragulla \& Homberger, 2007, 2009). Cornified digital end organs comprise hard-cornified horn segments as well as softcornified ones, at least in mammals (Table 2) (Bragulla \& Homberger, 2007, 2009). In mammals, the hard-cornified epidermis contains so-called hard keratin proteins, whereas the soft-cornified epidermis contains so-called soft keratin proteins. Soft-cornified epidermal structures 
Fig. 5 Scanning electron microscopy images of a medial view of the isolated distal phalanx of a cat (cat no. 21, male, older than 22-24 months; fifth digit of left forepaw) to show the complex structure of the distal phalanx and the dimension of the unguicular recess. (a) Intact distal phalanx. (b) Distal phalanx after the removal of the medial half of the unguicular hood.
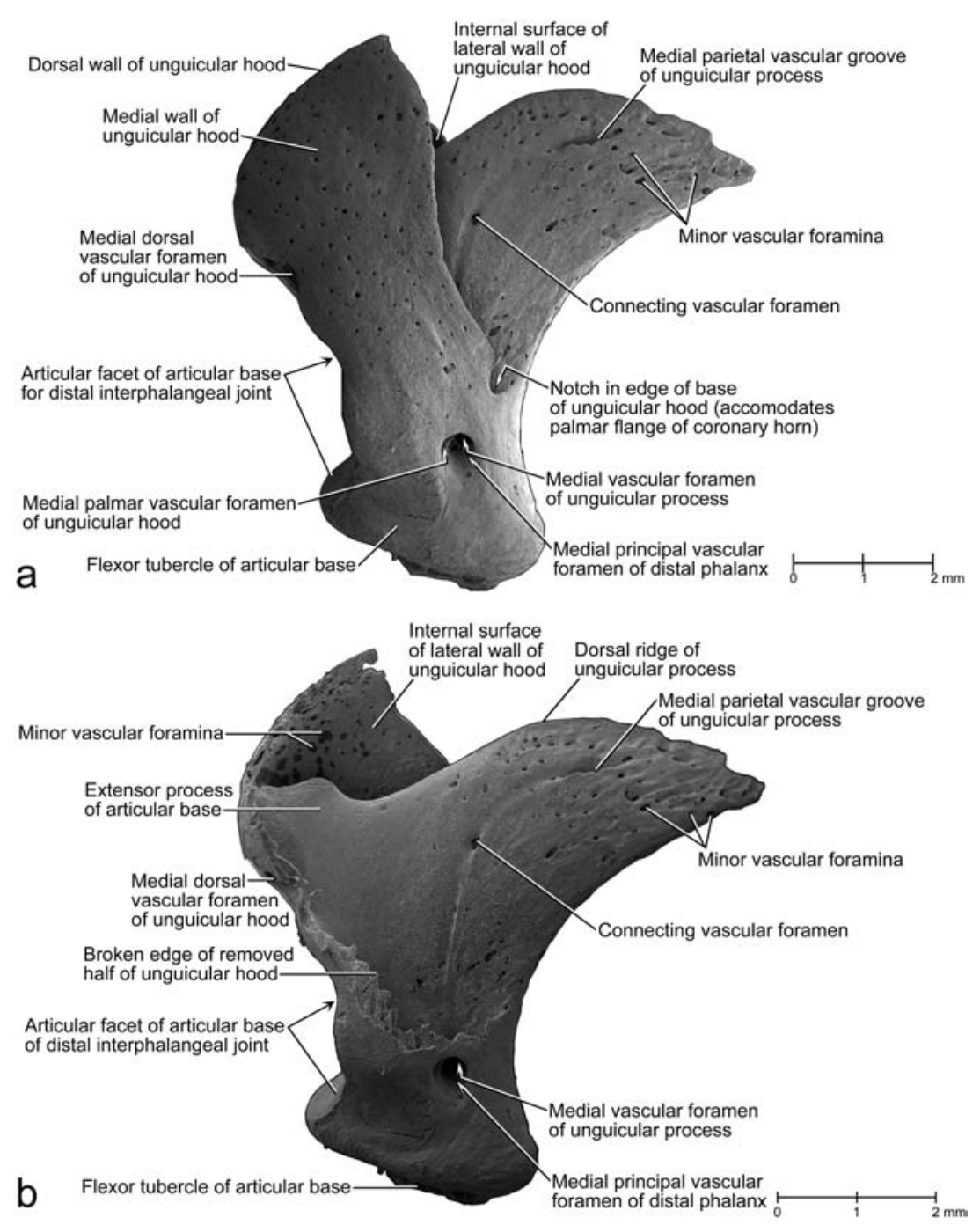

in mammals comprise the epidermis of the interfollicular skin, digital pads and soft-cornified segments of digital end organs. The qualitative differences (e.g. increasing stiffness) between these soft-cornified structures correlate with an increasing thickness of the stratum granulosum of the living epidermis and the stratum corneum. Some other differences may also derive from differences in the composition of the intercellular cementing substances binding the cornified cells within the stratum corneum.

In the following, the morphology of the cornified claw sheath is analysed by describing its various segments of horn and horn-generating living epidermis, as well as the functional properties of the horn segments within the cornified claw sheath and the relationships among the horn segments. Because the horn-generating living epidermis is generally located in a different place from where the horn material of the fully cornified epidermis is found, a preliminary discussion of growth processes, which are inferred from morphological observations, is usually included with the morphological description of the individual components of the cornified claw sheath. This approach to analysing growth processes is legitimate in the case of cornified digital end organs because the shape and location of the cornified epidermis can be compared with the shape and location of the horn-generating epidermis. The growth processes of the epidermis can be inferred from this comparison in the same way that lava flows from a volcano can be reconstructed from a comparison of the magma where it emerged from the earth and the cooled solidified igneous rock at the end of the flow. The inferences about the growth processes that mold the individual horn segments of the cornified claw sheath can be tested through their concordance with the integrated growth process of the cornified claw epidermis as a whole. They could also be tested through future developmental and biomolecular studies.

The growth and cornification of the claw epidermis proceed generally from the proximal root of the cornified 

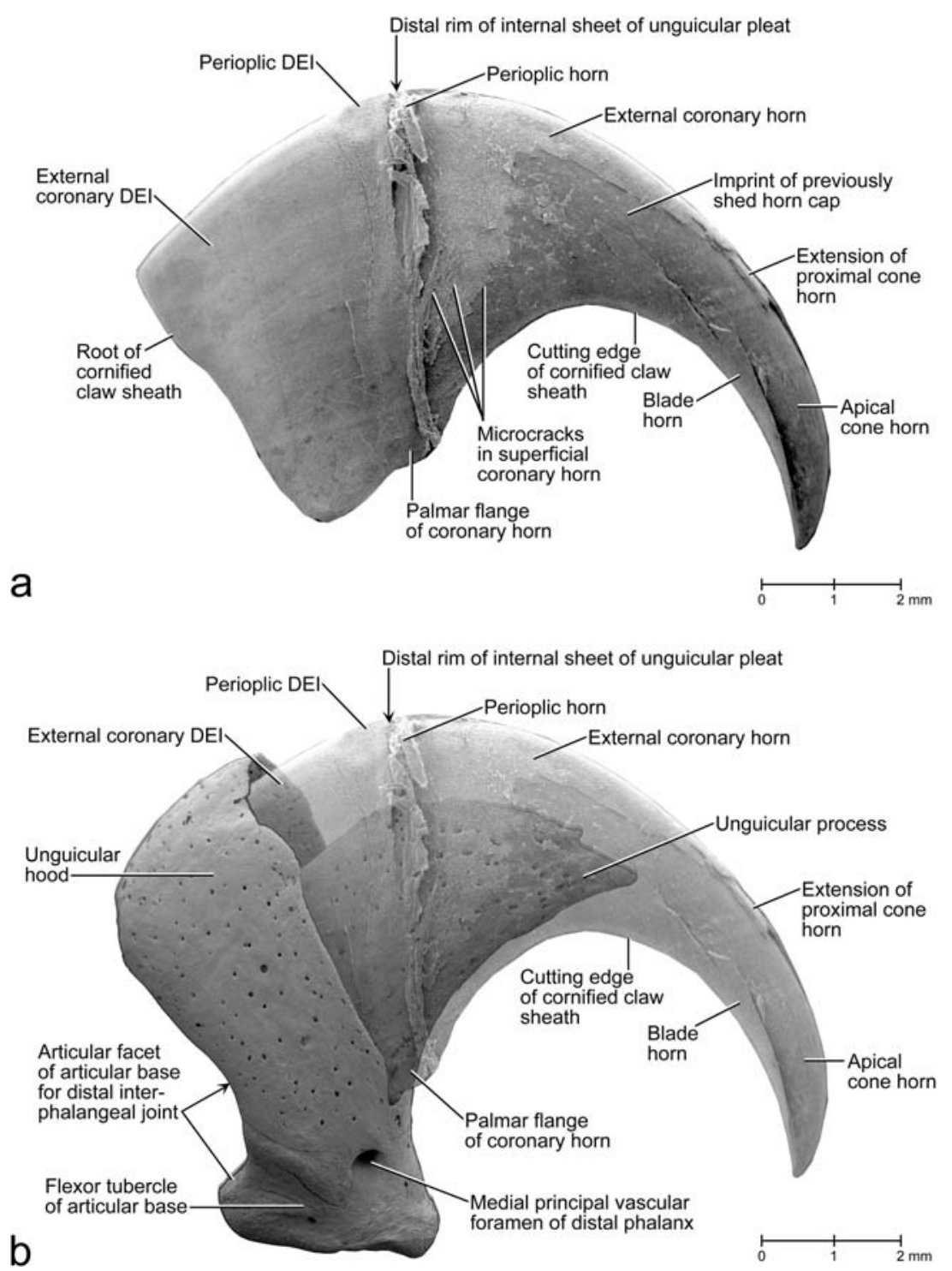

Fig. 6 Scanning electron microscopy images of a lateral view of the cornified claw sheath (including soft-cornified horn and living epidermis) of a cat (cat no. 18, fifth digit of right forepaw). (a) Surface view of the extracted and isolated cornified claw sheath (including soft-cornified horn and living epidermis) to show the superficial microcracks leading eventually to the shedding of horn caps off the tip of the cornified claw sheath, as well as the claw portion hidden from view in vivo. (b) Lateral view of the translucent cornified claw sheath (including soft-cornified horn and living epidermis) and medial view of the isolated distal phalanx of a cat (cat no. 21, male, older than 22-24 months; fifth digit of right forepaw; see also Fig. 5) to show the topographical relationship between the cornified claw sheath and distal phalanx. The mixing of the views and specimens was necessitated by the scarcity of intact specimens. DEl, dermo-epidermal interface. claw sheath towards its tip even though most of the living epidermis lies on the lateral and medial sides of the elongated, narrow claw and, hence, would be expected to generate horn perpendicularly to the claw surface and, thus, contribute to a broadening and thickening of the claw. The actual apical, rather than centrifugal, growth of the epidermis is the result of the root of the cornified claw sheath arising within the rigid unguicular recess and being pushed out of this recess by the proliferating living epidermis in the depth of the unguicular recess (see below for more details).

The distinct cracks that are visible between successive layers of hard-cornified coronary horn (e.g. Figs 7, 13) are artifacts that probably became more pronounced as a result of the desiccation in the course of processing. However, they are likely to have been preformed in vivo as a result of the natural drying of the cornified claw sheath when exposed to the environment and of the bending, shearing and tensile forces impinging on the cornified claw sheath as it is used in climbing and prey catching. These cracks are not continuous but can propagate through an entire layer of horn when a horn cap is shed (see later).

Of the three major horn divisions of the cornified claw sheath (see Tables 2 and 3), the most superficial horn division (i.e. the Eponychium) is represented by the softcornified perioplic horn. It is generated by the perioplic epidermis of the internal sheet of the unguicular pleat (Figs 3a,b, 4a-c). The friable perioplic horn protrudes distally from under the distal rim of the unguicular pleat (Figs $3 a, b, 6)$ and is soon abraded by natural wear and tear. It probably serves as a protective cushion for the underlying superficial layers of external coronary horn (see below). 
Table 3 Synonymies of the horn divisions of the cornified claw sheath and some associated structures in cats ${ }^{1}$

\begin{tabular}{|c|c|c|c|c|c|c|c|}
\hline \multicolumn{5}{|c|}{ Homberger et al. (this study) } & \multicolumn{3}{|c|}{ Siedamgrotzky (1871) } \\
\hline \multirow{2}{*}{$\frac{5}{\sim}$} & \multicolumn{4}{|c|}{ Skin pouch } & \multirow{2}{*}{$\underset{\substack{T \\
I}}{+}$} & \multicolumn{2}{|c|}{ Hautfalte, Vorhaut } \\
\hline & \multicolumn{4}{|c|}{ Unguicular pleat } & & \multicolumn{2}{|l|}{ Nagelfalz } \\
\hline \multirow{8}{*}{ 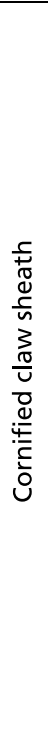 } & \multirow{7}{*}{$\begin{array}{l}\frac{5}{0} \\
\frac{0}{\bar{T}} \\
\frac{1}{3}\end{array}$} & \multicolumn{3}{|c|}{ Perioplic horn (Eponychium) } & \multirow{7}{*}{ 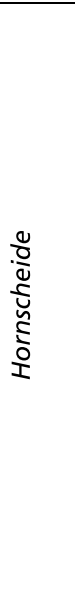 } & \multicolumn{2}{|c|}{$\begin{array}{l}\text { Part of the Seitliche Platte, not differentiated } \\
\text { from the external coronary horn }\end{array}$} \\
\hline & & \multirow{4}{*}{$\begin{array}{l}\text { Coronary } \\
\text { horn } \\
\text { (Meso- } \\
\text { nychium) }\end{array}$} & \multicolumn{2}{|c|}{ External coronary horn } & & \multirow{4}{*}{ Kra llenplatte } & $\begin{array}{l}\text { Part of Seitliche Platte; not } \\
\text { differentiated from the } \\
\text { perioplic horn }\end{array}$ \\
\hline & & & \multirow{3}{*}{$\begin{array}{l}\text { Internal } \\
\text { coronary } \\
\text { horn }\end{array}$} & Cone horn & & & Rückentheil, Hornkegel \\
\hline & & & & Crest horn & & & $\begin{array}{l}\text { Not identified as a separate } \\
\text { segment }\end{array}$ \\
\hline & & & & Blade horn & & & $\begin{array}{l}\text { Part of the Seitliche Platte, } \\
\text { not differentiated from the } \\
\text { external coronary horn }\end{array}$ \\
\hline & & \multirow{2}{*}{\multicolumn{2}{|c|}{$\begin{array}{l}\text { Horn of wall proper } \\
\text { (i.e., wall in the strict } \\
\text { sense) } \\
\text { (Hyponychium) }\end{array}$}} & $\begin{array}{l}\text { Parietal } \\
\text { horn }\end{array}$ & & \multicolumn{2}{|c|}{ Horn des Krallenbettes } \\
\hline & & & & $\begin{array}{l}\text { Terminal } \\
\text { horn }\end{array}$ & & \multicolumn{2}{|c|}{ Not differentiated from the sole horn } \\
\hline & $\frac{0}{\circ} \stackrel{ }{\circ}$ & Sole horn & & & 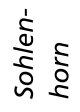 & Sohlenhorn & \\
\hline \multicolumn{5}{|c|}{ Living epidermis } & \multicolumn{3}{|c|}{ Schleimschicht } \\
\hline \multicolumn{5}{|c|}{ Basal layer of epidermis } & \multicolumn{3}{|c|}{ Matrix } \\
\hline \multirow{3}{*}{\multicolumn{2}{|c|}{$\frac{n}{\frac{\xi}{d}}$}} & \multicolumn{3}{|c|}{ Dorsal dermal papilla } & & \multicolumn{2}{|c|}{ Rückenwulst, Rückenpapille } \\
\hline & & \multicolumn{3}{|c|}{ Dermal frenulum } & $\cdot 2$ & \multicolumn{2}{|l|}{ Commissur } \\
\hline & & \multicolumn{3}{|c|}{ Parietal dermis; dermal claw bed } & 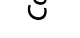 & \multicolumn{2}{|l|}{ Krallenbett } \\
\hline \multirow{3}{*}{\multicolumn{2}{|c|}{$\begin{array}{l}\frac{x}{c} \\
\frac{\pi}{\pi} \\
\frac{c}{2} \\
\frac{\pi}{\pi} \\
\frac{\pi}{0}\end{array}$}} & \multicolumn{3}{|c|}{ Flexor tubercle } & $\stackrel{x}{x}$ & \multicolumn{2}{|l|}{ Ballenhöcker } \\
\hline & & \multicolumn{3}{|c|}{ Unguicular hood } & $\frac{\pi}{\frac{0}{2}}$ & \multicolumn{2}{|l|}{ Knochenfalz } \\
\hline & & Unguicula & process & & $\underset{n}{N}$ & Körper & \\
\hline
\end{tabular}

${ }^{1}$ Only the structures that were named by Siedamgrotzky (1871) are listed.

The second major horn division (i.e. Mesonychium) is represented by the hard-cornified coronary horn with its several segments (Table 2). This coronary horn forms the actual cornified sheath of the claw. Its horn segments are identified individually mainly for didactic reasons; they are not sharply delimited from one another and in reality create a unit of hard-cornified horn, which is eventually shed as a horn cap off the tip of the cornified claw sheath. It is not always possible, especially not without very high magnification, to determine which particular coronary horn segment has become exposed on the surface of the cornified claw sheath; on such occasions we will use the more generalized term 'coronary horn'.

The hard-cornified external coronary horn is the most superficial horn segment of the coronary horn and is generated by the living external coronary epidermis, which is supported by the dermis that lines the internal surface of the unguicular hood (Figs 3a-c, 4a,c, 6, 7). Because of this orientation, the external coronary epidermis cornifies centripetally within the unguicular recess, although its cornifying cell layers are deflected apically by the proliferating living epidermis in the depth of the unguicular recess. The most superficial layer of the external coronary horn originates from the living epidermis along the distal rim of the unguicular hood. As it is pushed apically underneath the unguicular pleat, it is still in the process of cornifying and hardening. At this stage, the perioplic horn may serve as a protective cushion against the pressure exerted by the unguicular pleat, especially when the cornified claw sheath is being deformed in the course of the normal use of the claw (Fig. 3b) (this role of the perioplic horn was also suggested for the horse hoof by K.-D. Budras, personal communication). After the external coronary horn has emerged distally from underneath the distal rim of the 


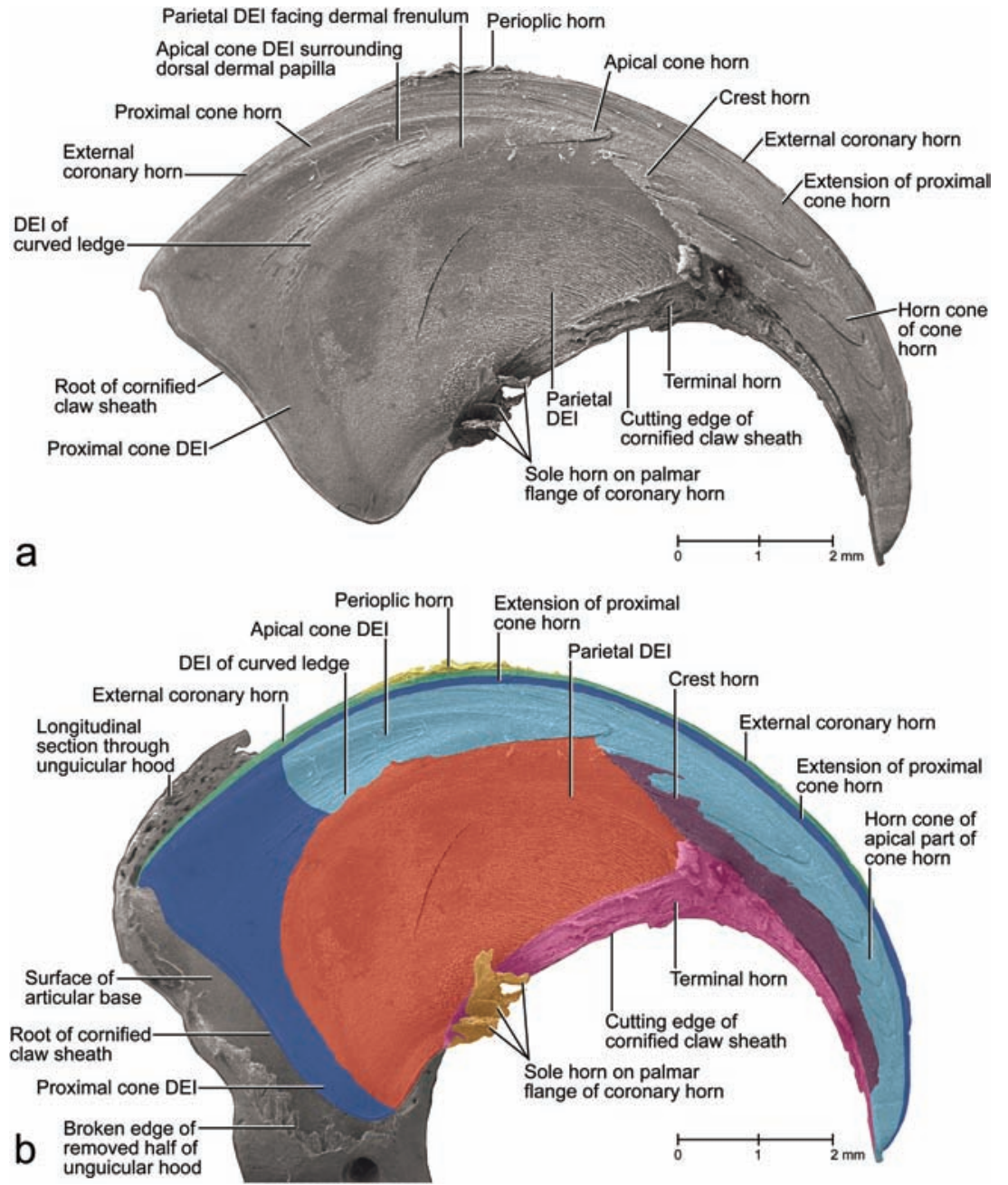

Fig. 7 Scanning electron microscopy images of the internal view of the medial half of the isolated cornified claw sheath (including the soft-cornified horn and living epidermis) of a cat (cat no. 18, fifth digit of right forepaw) to show the topography and architecture of the horn elements of the cornified claw sheath.

The perioplic, external coronary, crest, terminal and sole horn, as well as the superficial parts of the proximal cone horn and the horn cones of the apical cone horn, are shown in section. The dermo-epidermal interface (DEI) of the cone, blade and parietal horn is shown in a surface view. The threedimensional profile of the dermis can be inferred from the three-dimensional profile of the DEI. The microcracks between layers of sectioned horn segments develop during dehydration along stress lines that are dictated by the architecture of the horn material. (a) Isolated cornified claw sheath. The artifactual crack that is visible in the parietal DEI developed in the horn external to the parietal horn; it parallels the radial stress lines visible in the superficial coronary horn in Figs $8 a, 11 a$, b. (b) Color-coded isolated claw sheath reinserted within the unguicular recess of the distal phalanx (after the removal of the medial half of the unguicular hood) of a cat (cat no. 21, male, older than 22-24 months; fifth digit of left forepaw; see Fig. 5b) to show the topographical relationships of the internal architecture of the cornified claw sheath and distal phalanx. The articular base of the distal phalanx was graphically cut along the root of the cornified claw sheath. unguicular pleat, it is gradually abraded by natural wear before reaching the tip of the cornified claw sheath, as can be inferred from the proximo-apical thinning of the superficial layers of coronary horn and the exposure of blade and cone horn at the extreme claw tip (Figs 6, 7b, 13).

The internal coronary horn consists of three subdivisions (see Table 2), one of which is represented by the hardcornified cone horn. It is generated by the living cone epidermis, which is bounded on its medial and lateral sides by curved ledges that extend apically into the longitudinal troughs along the dermal frenulum (Figs 4, 7). The cone horn and epidermis can be subdivided into two intergrading parts, namely the proximal and apical cone horn (Figs 3c, 4, 7).

The proximal cone horn is the most superficial segment of the internal coronary horn (Table 2) and is generated by the living epidermis that is supported by the dermis covering the bony articular base within the unguicular recess (Figs 3, 4a,c, 7b). The proximal cone epidermis cornifies centrifugally within the narrow confines of the unguicular recess and, hence, butts against the cornifying layer of the external coronary horn (Fig. 3b,c). However, the cornify- ing cell layers of both the external coronary and proximal cone horn are deflected and pushed distally by the proliferating living epidermis in the depth of the unguicular recess (see above).

The combined external coronary and proximal cone horn forms the surface of the cornified claw sheath and is instrumental in inducing its palmo-apical curvature. Because the unguicular recess is much deeper on the dorsal side than on the medial and lateral sides (Figs 5b, 7b), the area of the combined living epidermis that generates the external coronary and proximal cone horn is more extensive on the dorsal side and gradually diminishes on the lateral and medial sides (Figs 7, 8b, 9b, 10b, 11a, $12 a, b)$. This configuration of the horn-generating external coronary and proximal cone epidermis results in a higher rate of horn production on the dorsal side of the claw than on its lateral and medial sides, and this unequal growth rate results in an apico-palmar curving of the superficial horn layers of the cornified claw sheath (i.e. the combined external coronary and proximal cone horn). These unequal growth rates are likely to create stresses within the proliferating epidermis of these superficial horn layers. 
Fig. 8 Mesoscopic digital photographs of the unpreserved isolated cornified claw sheath (including the living, horn-generating epidermis and parts of the epidermis of the unguicular pleat, skin pouch and skin fold connecting the palmar flanges of the coronary horn) of a cat (cat no. 24, Persian adult male, fifth digit of left forepaw). The frayed tip of the cornified claw sheath may be the result of the maceration procedure. The faint radial ridges of opaque tissue [visible in (a) and (b)], which diverge from the proximo-palmar end of the cornified claw sheath, are formed by the proximal cone epidermis underneath the external coronary horn. (a) Lateral view. (b) Lateroproximo-palmar view. (c) Proximo-palmar view. DEI, dermo-epidermal interface.

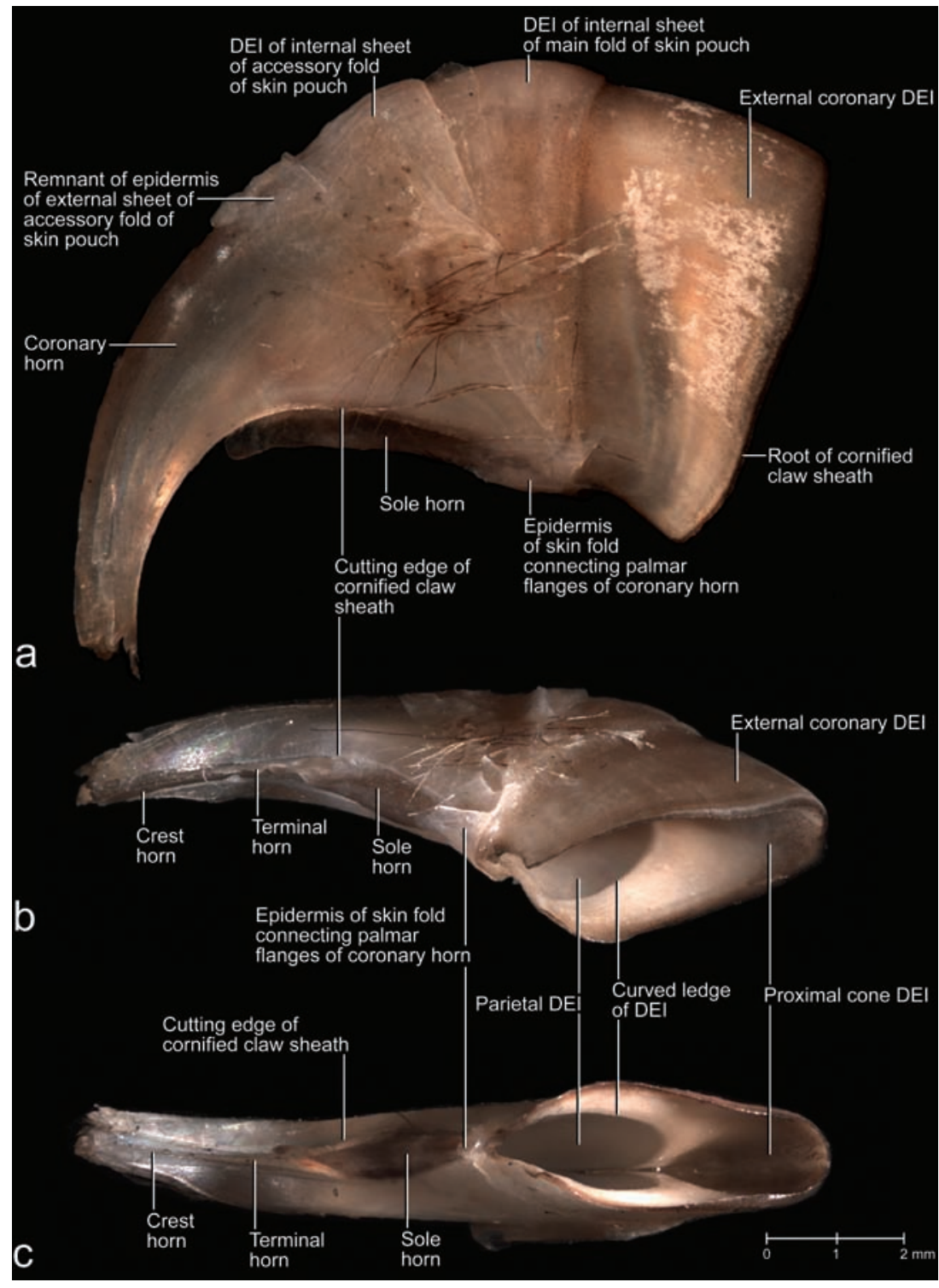

These stresses may be responsible for the radial ridges of thickened horn that radiate dorso-apically from the proximo-palmar corner of the cornified claw sheath (Figs 8a, $10 a, b, 11 a)$ and are also discernible on the parietal dermoepithelial interface (Fig. 9b) and even the internal surface of the stratum corneum.

Because the curvature of the combined external coronary and proximal cone horn is already established by the time it is fully cornified and reaches the more apical and internal segments of the internal coronary horn (i.e. the apical cone, blade, parietal and crest horn; see below and Table 2), it serves as a mold to which the more apical horn elements need to adjust. The underlying living epidermis and dermis, which function as hydraulic entities, are likely to transmit the pressure from the curving cornified claw sheath to the surface of the bony unguicular process. Hence, the dorsal curve of the unguicular process may have developed in response to the curving cornified claw sheath and may, in turn, stabilize the curvature of the cornified claw sheath by anchoring it through the connective tissue of the dermis. However, in order for the cornified claw sheath not simply to follow the dorsal curve of the unguicular process, but instead generate a pointed tip that projects palmo-apically beyond the tip of the unguicular process, additional horn has to be generated on an apically projecting dorsal dermal papilla (Figs 3a, 4a,c, 7).

The horn-generating apical cone epidermis seamlessly extends distally from the proximal cone epidermis and is supported by the dorsal dermal papilla (Figs 3, 4a,c, 7, 9b). The portion of the apical cone horn that is generated over the free tip of the dorsal dermal papilla is arranged in conical layers (Fig. 7). These horn cones eventually form the pointed tip of the cornified claw sheath (Figs 7, 13c). The living apical cone epidermis at the base of the dorsal 

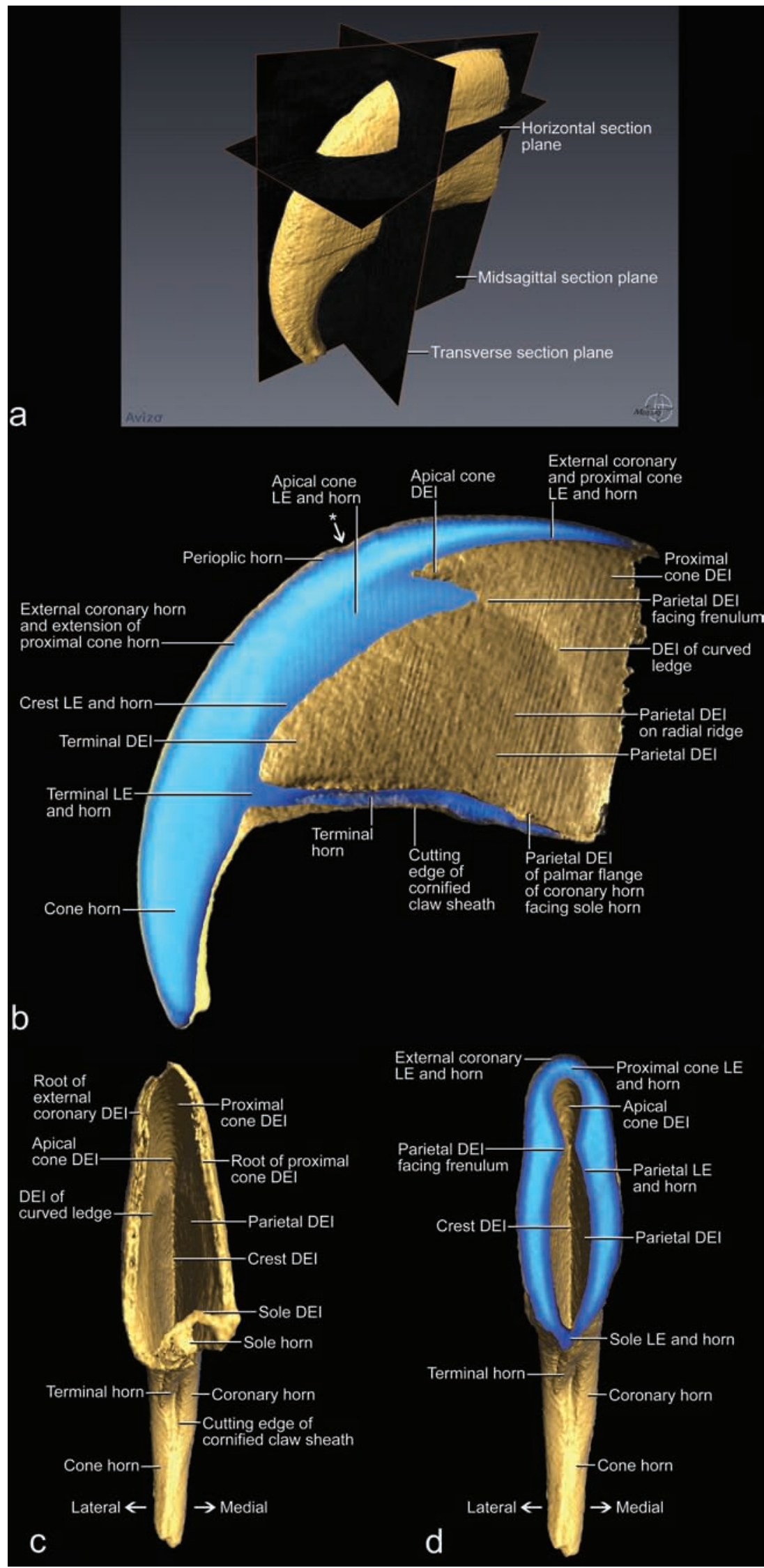

Fig. 9 Images of an unpreserved isolated cornified claw sheath (including the underlying living, horn-generating epidermis) of a cat (cat no. 24, Persian adult male, fifth digit of left forepaw) reconstructed and visualized from $\mathrm{x}$-ray computed tomography data $(40 \mathrm{kVp}$ polychromatic $x$-ray beam; field of view of $28 \mathrm{~mm}$ in diameter and $19 \mathrm{~mm}$ in height; voxel side length of $37 \mu \mathrm{m})$. Section planes are shown in blue (although lighter shades are indicative of greater density, this relationship is not absolute in this rendering because of distortions along the edges); surfaces are shown in gold. The striations on the gold surfaces are artifacts. The epidermis of the unguicular pleat, skin pouch and skin fold connecting the palmar flanges of coronary horn was apparently not dense enough to absorb $x$-rays and be visualized. (a) Oblique rostro-dorso-lateral view with section planes that were applied in (b-f). (b) Medial view of median section. (c) Proximal view of the isolated cornified claw sheath. (d) Proximal view after a virtual transverse section at the level of the dermal frenulum. (e) Horizontal section at the level of the maximal extent of the dorsal dermal papilla. The space framed by the cone dermo-epithelial interface (DEI) would be filled by the dermal frenulum in the intact claw. (f) Horizontal section at the level just below the palmar edge of the base of the dorsal dermal papilla. LE, living epidermis; *, distal rim of the unguicular pleat. 
Fig. 9 Continued
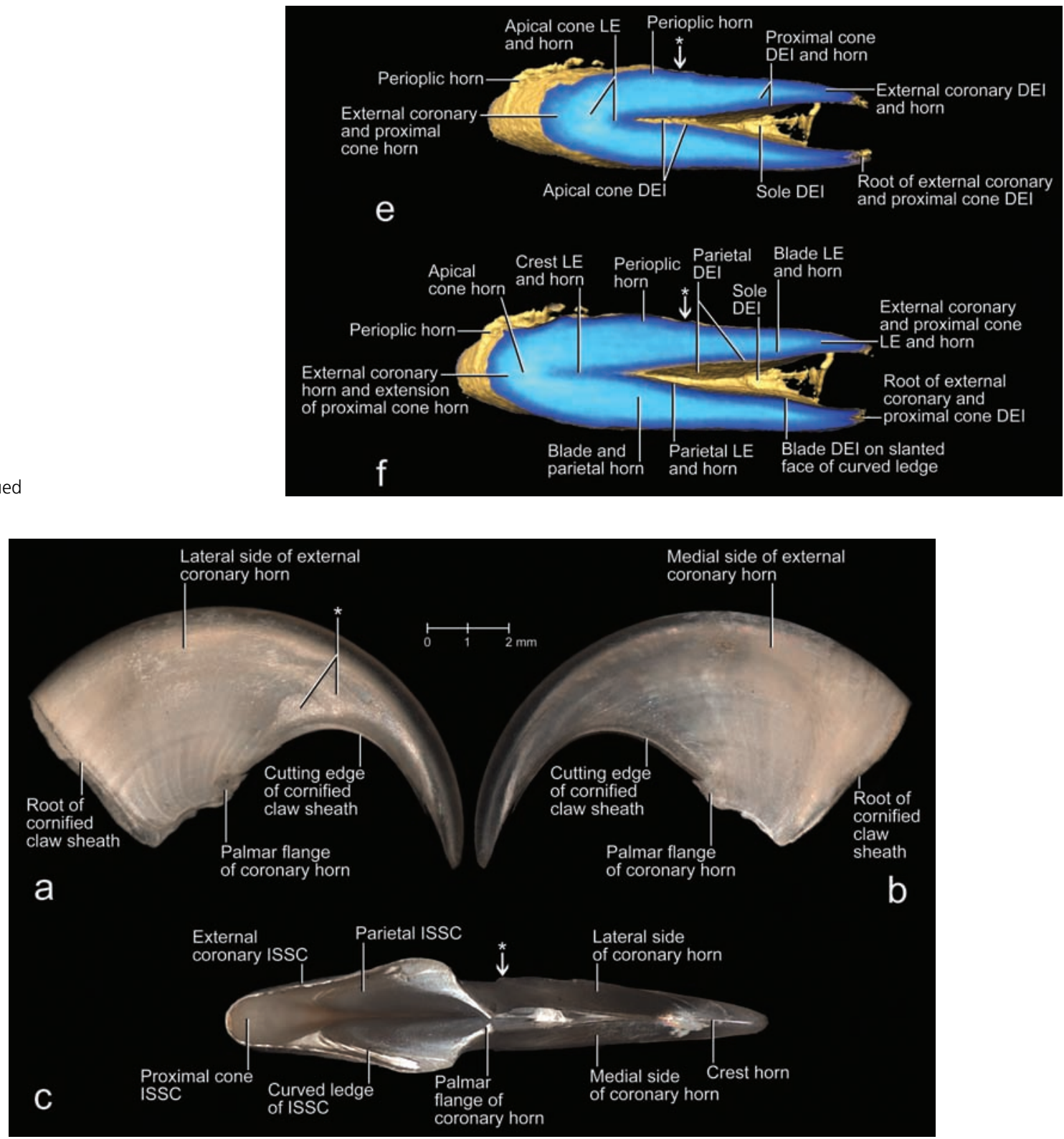

Fig. 10 Mesoscopic digital photographs of an unpreserved isolated hard-cornified claw sheath without soft-cornified horn or living epidermis (cat no. 45R, spayed adult female, fifth digit of right forepaw). The radial ridges of opaque tissue [visible in (a) and (b)], which diverge from the proximo-palmar end of the cornified claw sheath, are formed by the proximal cone epidermis underneath the external coronary horn. (a) Lateral view. (b) Medial view. The curved ledge, as well as the blade horn growing distally from it, are visible through the translucent external coronary horn.

(c) Palmar view. Notice the several blades of blade horn, especially on the lateral side of the cornified claw surface. ISSC, internal surface of the stratum corneum (i.e. the interface between the living and cornified epidermal layers); ${ }^{*}$, superficial layer of coronary horn to be shed eventually as part of a horn cap (see Fig. 14b).

dermal papilla transitions into the horn-generating parietal epidermis on the palmar side of the dorsal dermal papilla where it is tethered by the dermal frenulum to the dermis covering the unguicular process (Fig. 4b). As a result, the horn cones generated by this basal portion of the apical cone epidermis are split on their palmar side by the crest horn (see below; Figs 13b, 14a,b).

The hard-cornified crest horn, which is another segment of the internal coronary horn (Table 2), is generated by the living crest epidermis that is supported by the dermis on the distal edge of the dermal frenulum and along the dorsal crest of the bony unguicular process (Figs 7a, 9c, d, $f$, $12 a, b, e, g, i)$. The crest horn fills the apical cleft on the palmar side of the apical cone horn forming the tip of the cornified claw sheath (Figs 13b, 14a,b).

The hard-cornified parietal horn is a segment of the third major horn division (i.e. the Hyponychium; see Table 2); it is described at this point for didactic reasons (i.e. before 


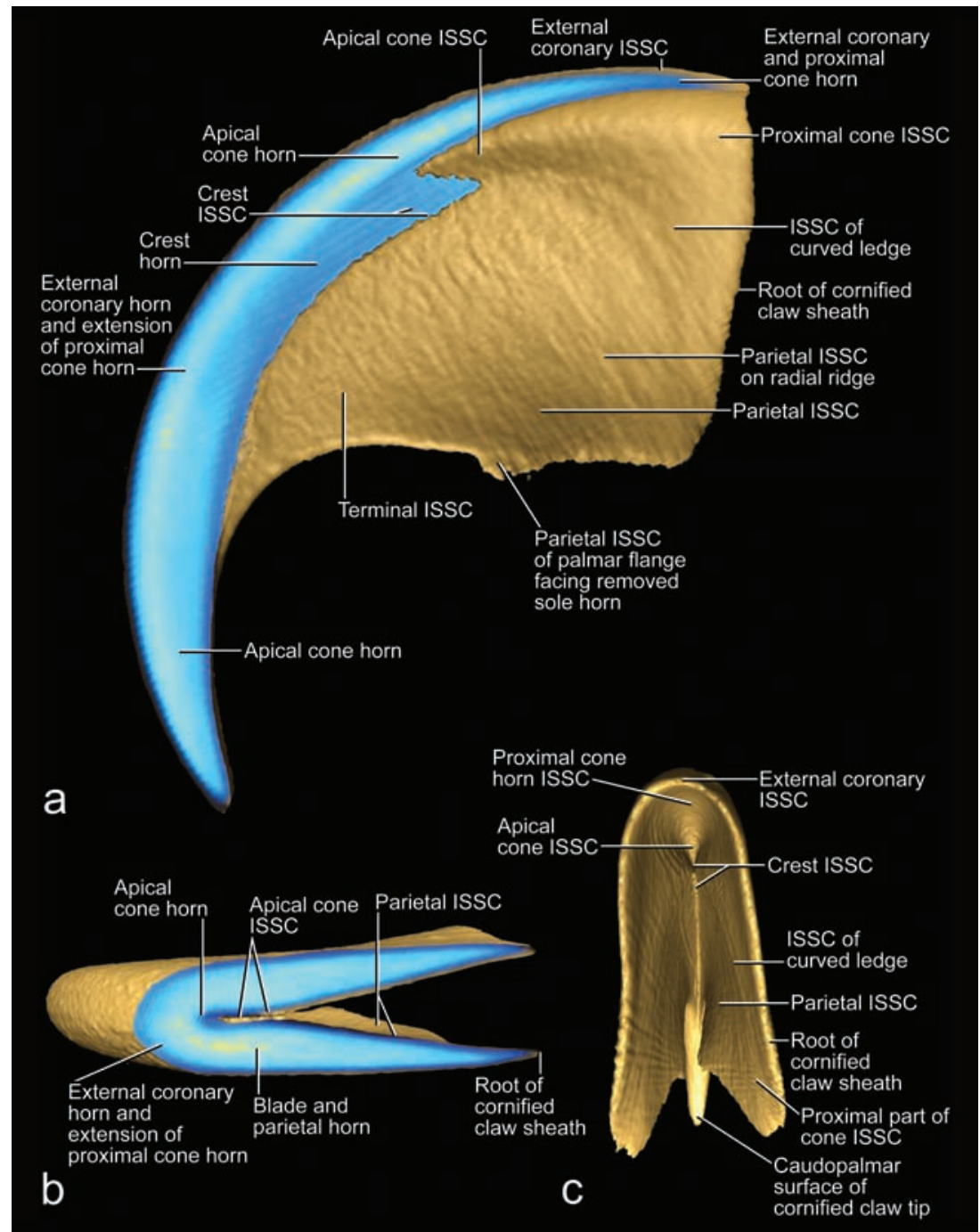

Fig. 11 Images of an isolated unpreserved hard-cornified claw sheath without living and soft-cornified epidermis of a cat (cat no. 45R, spayed adult female, fifth digit of right forepaw) reconstructed and visualized from x-ray computed tomography data $(40 \mathrm{kVp}$ polychromatic $x$-ray beam; field of view of $28 \mathrm{~mm}$ in diameter and $19 \mathrm{~mm}$ in height; voxel side length of $37 \mu \mathrm{m}$ ). Sectioned planes are shown in blue (although lighter shades are indicative of greater density, this relation is not absolute in this rendering because of distortions along the edges); surfaces are shown in gold. The actual three-dimensional profile of the internal surface of the stratum corneum (i.e. the interface between the living and cornified epidermal layers) (ISSC) may be easier to visualize if the figure is held upsidedown because of an optical illusion. (a) Media view of median section. (b) Oblique horizontal section at the level of the maximal extent of the dorsal dermal papilla. (c) Proximal view. completing the description of all segments of the internal coronary horn). The horn-generating parietal epidermis is supported by the dermis that forms the dermal frenulum and covers the sides of the bony unguicular process palmo-distally from the cone epidermis (also called the dermal claw bed) (Figs 4b, 7, 8a,b, 9b-d,f, 12a,b,e,g,i, 13a). Although the parietal epidermis proliferates centrifugally, its cornifying epidermal layers are deflected apically by the cornifying epidermis that is generated by the living blade epidermis (see below). The parietal horn is relatively thin, as can also be inferred from the artifactual cracks that appear in desiccated specimens (Fig. 7a). The artifactual crack within the parietal dermo-epidermal interface (Fig. 7a) parallels the radial cracks seen on the surface of the coronary horn near the unguicular pleat on the palmo-lateral and palmo-medial sides of the cornified claw sheath (Fig. 6a) and may have been propagated from the proximal cone horn through the blade horn into the parietal horn. Similarly, the crack through the parietal dermo-epidermal interface facing the dermal frenulum
(Fig. 7a) is continuous with a more distal crack in the apical cone horn and was propagated through the parietal horn.

The hard-cornified blade horn is a segment of the internal coronary horn (Table 2 ) and is generated by the living blade epidermis that is supported by the dermis on the slanted face of the curved ledge (Figs 4b, 8b,c, 9b, $f$, $12 a, b, e, g, i, 13 a)$. Most of the blade horn originates from the part of the curved ledge whose face is oriented latero-apically or medio-apically (depending on the side of the claw), so that it is pushed apically by the living blade epidermis (instead of growing centrifugally) with a gentle curve towards the tip of the unguicular process. The blade horn that originates from the more dorsal part of the curved ledge, where it bends distally, is pushed distally along the parietal horn within the longitudinal trough on the sides of the dermal frenulum (see above; Fig. 4b). Distally, it follows the palmar bend dictated by the curving external coronary horn and the proximal and apical cone horn of the cornified tip of the claw. The blade horn forms (together with the overlying combined horn layer of the 
Fig. 12 Images of virtual casts of the internal volumes enclosed by isolated cornified claw sheaths of cats and reconstructed from $x$-ray computed tomography data $(40 \mathrm{kVp}$ polychromatic $x$-ray beam; field of view of $28 \mathrm{~mm}$ in diameter and $19 \mathrm{~mm}$ in height; voxel side length $37 \mu \mathrm{m}$ ) and processed with visualization software that was supplemented by external computational processing. The palmar surface of the virtual casts are artificial and do not represent the actual surfaces. (a, b, e, g and i) Three-dimensional profiles of the dermis reconstructed from virtual casts of the internal volume enclosed by the complete epidermis, i.e. the isolated cornified claw sheath with the underlying living, horn-generating epidermis (cat no. 24, Persian adult male, fifth digit of left forepaw). ( $c, d, f, h$ and $j$ ) Three-dimensional profiles of the living and soft-cornified epidermis reconstructed from virtual casts of the internal volume enclosed by the hard-cornified epidermis, i.e. the isolated hard-cornified claw sheath without living and soft-cornified epidermis (cat no. 45R, spayed adult female, fifth digit of right forepaw). (a and c) Medial views. ( $b$ and $d$ ) Lateral views. (e and $h$ ) Disto-medial views. ( $f$ and g) Disto-lateral views. (i and j) Distal views. DEl, dermo-epidermal interface; ISSC, internal surface of the stratum corneum (i.e. the interface between the living and cornified epidermal layers).

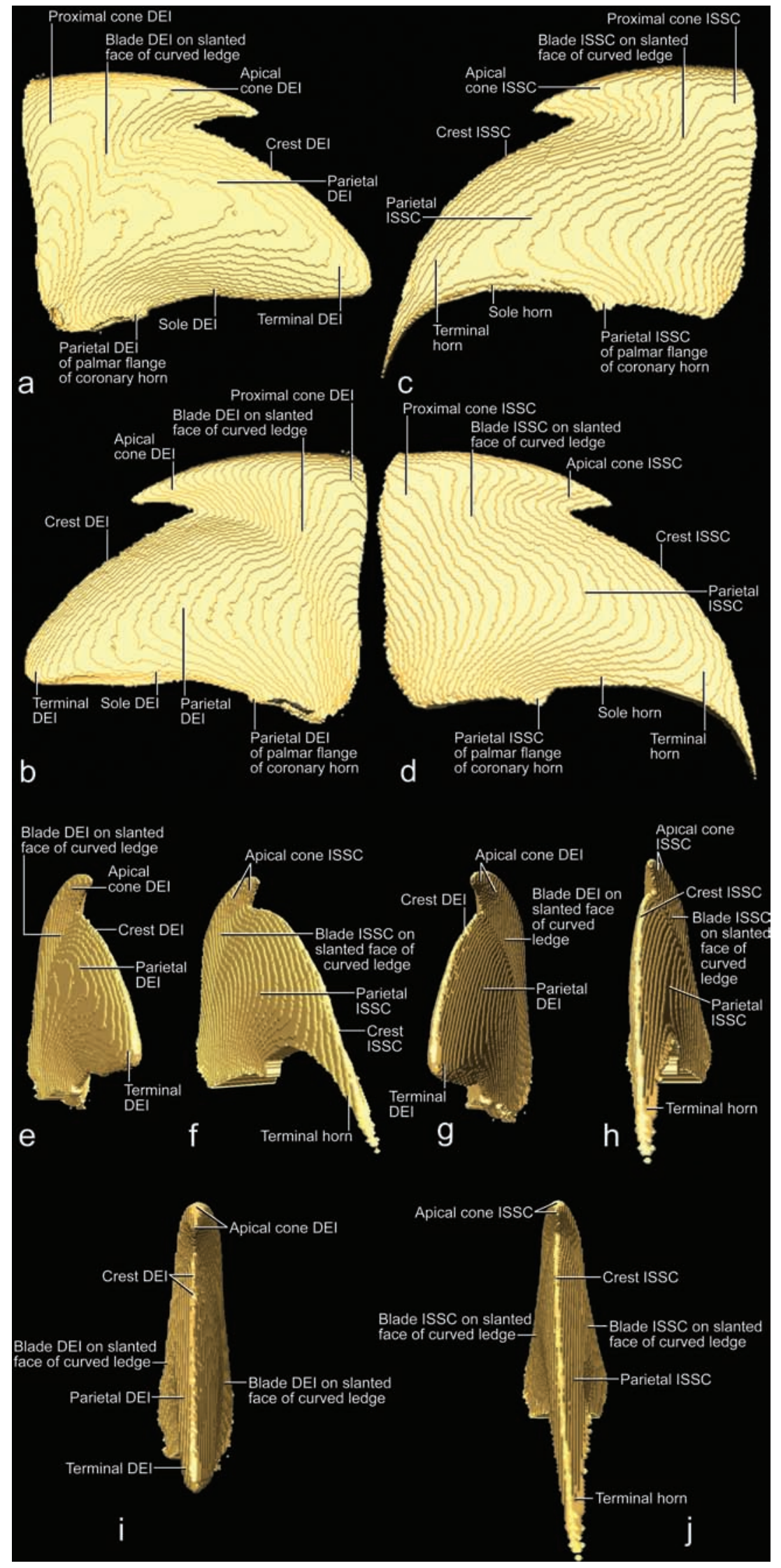




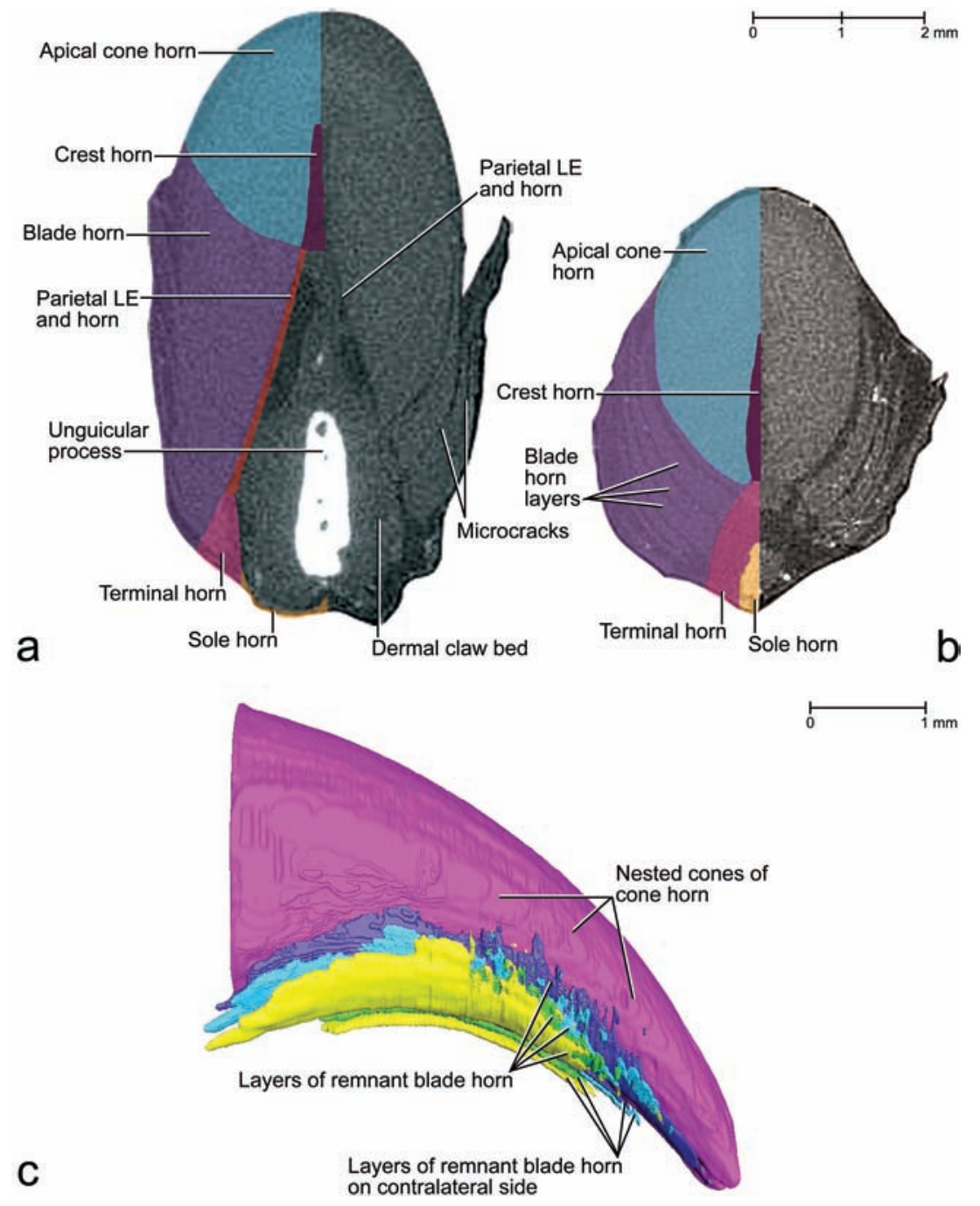

Fig. 13 Images of the tip of a claw of a cat (cat no. 12, adult, fifth digit of left forepaw) based on phase-contrast enhanced $x$-ray computed tomography data (20 keV monochromatic synchrotron $x$-ray beam; field of view of $7.19 \mathrm{~mm}$ in diameter and $5.7 \mathrm{~mm}$ in height; scintillator distance to specimen $330 \mathrm{~mm}$; voxel side length $11.06 \mu \mathrm{m}$ ) and manual segmentation. ( $a$ and $b$ ) Transverse sections to show the development of microcracks through the coronary horn (including the external and internal coronary horn and blade horn). (a) Section at the level near the distal tip of the unguicular process. (b) Section at the level slightly distal to the distal tip of the unguicular process.

(c) Visualization of a three-dimensional reconstruction of the distal one-third of the cornified claw sheath to show the surface configuration of horn blades that are separated by microcracks. The color scheme used in (c) does not correspond to the color scheme in (a), (b) and the other color-coded figures. LE, living epidermis.

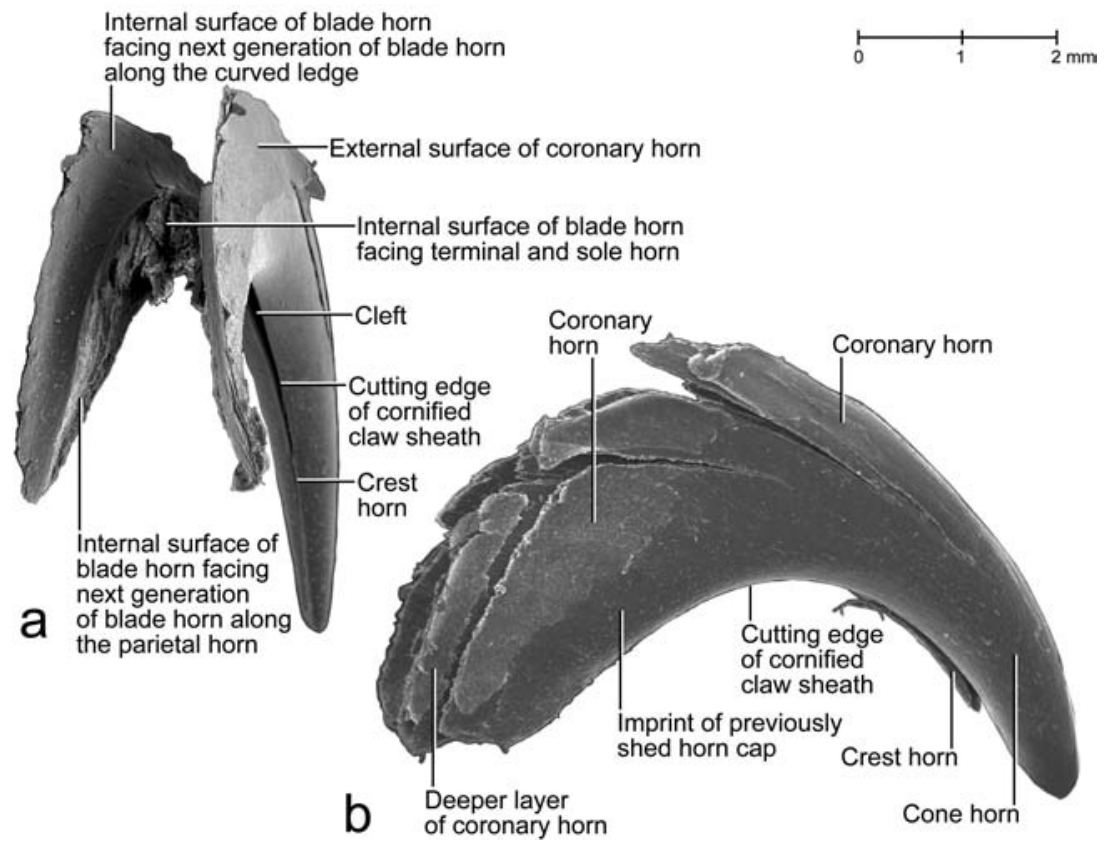

Fig. 14 Scanning electron microscopy picture of shed horn caps off the tips of cornified claw sheaths of an adult female cat. (a) Proximal view (specimen SC no. 3). (b) Side view (specimen SC no. 5). 
external coronary and proximal cone horn) the core of the cutting edge of the cornified claw sheath (Figs $6,8,10$ ).

The horn-generating living blade epidermis that is located most centrally on the slanted face of the curved ledge is continuous with the parietal epidermis (Fig. 9b), so that the blade epidermal cells generated here lie next to the parietal epidermal cells. Therefore, the cornifying parietal epidermal cells are deflected and entrained apically as the blade horn is pushed apically by the proliferating living blade epidermis. The direction in which the blade horn is pushed forward can also be inferred from the arrangement of the ridges visible on the dermo-epidermal interface of the parietal horn (Fig. 7). The living blade epidermis that is located at the outer edge of the face of the curved ledge is continuous with the living epidermis of the proximal cone horn (Fig. 9b). These lateralmost blade epidermal cells, therefore, form a layer that lies directly underneath the deepest layer of proximal cone horn, so that the boundary between the blade horn and proximal cone horn is indistinct. Hence, the layers of horn that are generated in the dorso-proximal bend of the curved ledge underneath the combined horn layer of the external coronary and proximal cone horn cover the sides of the apical cone horn and are designated as part of the blade horn. As the superficial coronary horn on the dorsal side of the cornified claw sheath is worn off through normal use, the superficial layers of the blade horn are exposed and are shown to hug the sides of the apical cone horn (Fig. 13a). Remnants of these blade horn layers are discernible near the very tip of the cornified claw sheath, which consists mostly of apical cone horn, because the rest of the coronary horn, including most of the blade horn, has been worn off (Fig. 13b,c).

The remaining soft-cornified horn segments of the cornified claw sheath are found in places where the hard-cornified horn divisions need to be supported and cushioned.

The soft-cornified terminal horn is a segment of the third major horn division (i.e. the Hyponychium; see Table 2). It is generated by the living terminal epidermis, which is continuous caudally with the parietal living epidermis and is supported by the dermis that covers the medial, lateral and palmar sides of the tip of the bony unguicular process (Figs 3a, 4a,c, 7, 9b, 11a, 12a-j). It supports the apical cone and crest horn on its dorso-distal side (Figs 3a, 4a,c, 7, 9b, 13b) and the blade horn on its lateral and medial sides (Figs 4b, 8, 9b-d, 13a,b). By filling the space created by these converging segments of hard-cornified internal coronary horn, it is shaped into an elongated, pointed cone and extends proximally between the blade and sole horn (Figs 12c,d,f,h,j, 13a,b). Because the terminal horn is soft-cornified, it can adjust its shape to the changing conformation of the space it fills in the course of the deformations of the cornified claw sheath during its normal use.
The friable soft-cornified sole horn is generated by the living sole epidermis, which is supported by the dermis that covers the proximo-palmar side of the bony unguicular process (Figs 3a, 4, 7, 8, 9b-e, 12c,d, 13a,b). Along its medial and lateral sides, it is embraced by the terminal and parietal horn (Figs 1b, 4b, 8, 9c,d, 13a,b). The sole horn, therefore, fills the space between the paired cutting edges of the cornified claw sheath. It is worn off through natural wear and tear, as well as through repeated compression and release, as the cornified claw sheaths are deformed when they are subjected to tensile forces during climbing and prey capture.

\section{Discussion}

Whereas most studies and textbooks that describe claws limit themselves to a very basic description of the hard wall horn, the softer sole horn and some cutaneous structures (e.g. Boas, 1931; Habermehl, 1981; Starck, 1982; Banks, 1986; Al-Bagdadi, 1993; Bragulla et al. 2001; Hamrick, 2001, 2003; Dyce et al. 2002), the impressive study of the cornified digital end organs of herbivores and carnivores by Siedamgrotzky (1871) may well be regarded as the most detailed and biologically relevant description of the cornified claw sheath of cats and dogs to date (see also Vollmerhaus \& Roos, 2000). Although our own observations, which were made independently, were able to confirm many of the basic observations of Siedamgrotzky (1871) (see Table 3), they also considerably expanded them with fresh and new conceptualizations, structural details, functional interpretations and visual representations based on the technical advances of the last 140 years. In our discussion of the functional interpretations of Siedamgrotzky (1871), we used our own terms and compiled Table 3 to correlate our own terms and conceptualizations with those of Siedamgrotzky (1871).

Our study confirms the determining role of the threedimensional profile of the dermo-epidermal interface for the shape and internal architecture of cornified organs (see also Bragulla et al. 2001; Homberger, 2001). The avascular epidermis that generates the cornified claw sheath is supported not only metabolically but also mechanically by the underlying vascularized and innervated connective tissue of the dermis, whose three-dimensional profile differs from that of the supporting bony distal phalanx. Hence, the three-dimensional visualization of the dermis and dermo-epidermal interface is crucial for an integrated understanding of the architecture of the cornified claw sheath and has been facilitated by the use of recently developed imaging and visualization techniques that are described in this study. As a result, a more accurate understanding of the complex architecture of the cornified claw sheath was made possible and prepared the ground for an analysis of the claw-shedding mechanism, which is typical of domesticated cats but may also occur in other mammals and terrestrial tetrapods. 
Our functional analysis of the cornified claw sheath is based on an integrative and holistic approach, which considers as many aspects and features of a complex organ as possible, including its associated structures, with the understanding that these aspects and features are structurally and functionally interacting and interdependent. This approach includes an abstraction a posteriori (i.e. after an organ has been understood in its intrinsic complexity) in contrast to the more common approach of an abstraction a priori, in which a system is reduced to simpler components in order to facilitate its analysis.

\section{Functional morphological analysis of the cornified claw sheath and its associated structures}

The salient features of the cornified claw sheath of cats and its associated structures are (1) the ossified unguicular hood forming the unguicular recess; (2) the apical cone horn formed on top of the dorsal dermal papilla and forming the hardened tip of the cornified claw sheath; and (3) the newly described blade horn generated by the epidermis on the face of the curved ledge.

An ossified bony unguicular hood is part of the distal phalanx in carnivores and edentates (Boas, 1931). Siedamgrotzky (1871) and Boas (1931) hypothesized that the ossified unguicular hood serves to anchor the cornified claw sheath in mammals that experience large pulling forces on their cornified claw sheaths when they use their claws to dig or to catch prey. Siedamgrotzky (1871) and Habermehl (1981) also observed that the unguicular hood and recess are less extensive in dogs than in cats, which are believed to experience greater tensile forces on their claws. Our observations broadly support the hypothesis of Siedamgrotzky (1871). The unguicular recess that lodges the living epidermis generating the root of the cornified claw sheath is formed by fibrous connective tissue in most mammals and also in newborn cats. During the first 18-24 months, this fibrous connective tissue gradually ossifies until the growth plate of the distal phalanx has stopped growing, allowing the articular base to reach its adult size. This ossification process is likely to be stimulated and maintained by large tensile forces on the cornified claw sheath and, thus, on the underlying connective tissue. In turn, an ossified wall of the unguicular recess provides a stable attachment place that is less likely to be deformed by tensile forces than connective tissue would. The comparative observations of Siedamgrotzky (1871) provide further support for this interpretation of the functional role of an ossified, as opposed to a fibrous, unguicular hood. Small dogs, which tend to engage in digging activities more than large dogs, also possess longer ossified unguicular hoods than large dogs. The longest ossified unguicular hoods are seen on the terminal phalanges of anteaters, which tear apart termite hills to reach their prey. However, this interpretation needs to be tested further by analysing the walls of the unguicular recesses of the claws of other mammals and birds (e.g. rabbits and woodpeckers) that inflict large tensile forces on their claws.

In trying to explain further the adaptive advantage of an ossified unguicular hood, Siedamgrotzky (1871) thought that the combined horn layer of external coronary and proximal cone horn would be harder if it were formed within an unguicular recess that is formed by a bony unguicular hood than if it were formed within an unguicular recess that is formed by a fibrous unguicular hood, as in most mammals and birds. He argued that the cornifying cells that are generated within the rigid confines of an unguicular recess underneath an ossified unguicular hood are more compressed and flattened, and, hence, hardened. Although this hypothesis is tempting in its logic, our own observations do not support this interpretation, at least not in its current form. Coronary horn, including the horn that is formed in an unguicular recess, is hard-cornified and is generally very hard, even without the presence of an ossified unguicular hood. The reason for this may be that the taut connective tissue, as in ligaments, is capable of resisting pressure, such as that exerted by the proliferating epidermis within the unguicular recess. It is also unclear why the cornified claw sheaths of cats would need to be especially hardened, as young cats, whose unguicular hoods are still incompletely ossified, are quite capable of performing all of the necessary behaviors.

Siedamgrotzky (1871) also observed that the unguicular recess is deeper on the dorsal side than along the medial and lateral sides of the cornified claw sheath, thereby creating an enlarged area for the production of horn dorsally, which would lead to a higher rate and larger number of horn cells generated dorsally than on the medial and lateral sides. As Siedamgrotzky (1871) realized, the apical cone horn, which is generated by the living epidermis supported by the dorsal dermal papilla, is likely to follow the curvature that is prescribed by the external coronary and proximal cone horn, which is generated more proximally and, therefore, is more mature and harder than the apical cone horn at any given level of the cornified claw sheath. Our study confirms and supports these observations but also shows that the surface area of the horn-generating external coronary and proximal cone epidermis is disproportionately longer dorsally than on the sides even if the unguicular hood is not completely ossified. The same variation in the depth of the unguicular recess is observable in claws whose unguicular hood never ossifies and seems to be responsible for the curved growth of claws in general, irrespective of whether the unguicular hood is ossified or not. Hence, the ossification of the unguicular hood by itself may not be instrumental in generating a curved claw. However, the explanation for a curved growth of cornified claw sheaths could be refined by analysing the relationship between the relative depth 
of the unguicular recess on the dorsal side of a claw and the radius of its curvature. A natural experiment to this effect is readily available by comparing the claws on the front paws of cats with those on the hind feet, which are less strongly curved.

In more general terms, the presence of an unguicular hood (irrespective of whether it is fibrous or ossified), including its distal extension by the unguicular pleat and the concomitant formation of an unguicular recess, is responsible for ensuring that the horn that is generated by the living epidermis is pushed apically. In the absence of an unguicular recess, as is the case in amphibians, the horn layers that are generated by the underlying living epidermis accumulate on the surface and eventually form a thick cornified cap that projects from the surface of the unmodified skin (see Maddin et al. 2009). Future studies on the evolution of amniote claws may indicate when an unguicular recess and an apical growth direction of the cornified end organs first appeared during the evolutionary history of vertebrates.

According to Siedamgrotzky (1871), the dorsal dermal papilla is much longer with a much narrower dermal frenulum and the generated apical cone horn is more prominent in the claws of cats than in those of dogs. Siedamgrotzky (1871) also described that the proximal part of the dorsal dermal papilla of small dogs is more clearly separated from the dermal claw bed enveloping the unguicular process by a narrower dermal frenulum than that of larger dogs. This morphological difference is related to a behavioral difference with smaller dogs, such as dachshunds, engaging more frequently in digging with their forepaws than larger dogs. Siedamgrotzky (1871) further elaborated that the apical cone horn is less prominent in the cornified claw sheaths of small dogs than in those of cats and even less developed in large dogs, whose claws are blunt. These observations led Siedamgrotzky (1871) to identify the apical cone horn as the part of the cornified claw sheath that is responsible for generating a sharp, hardened tip of claws. Our own morphological observations support this interpretation, which will, however, need to be tested further by comparing the shape of cornified claw sheaths of mammals [e.g. the mouse and at least some neotropical opossums (Hamrick, 2001, 2003)], whose dermal claw beds do not form a dorsal dermal papilla. However, it seems that the capacity to form a dorsal dermal papilla and the concomitant sharp-tipped cornified claw may have evolved at an early stage of tetrapod evolution, as it has been documented in extant lizards (e.g. Starck 1982; Maddin et al. 2009).

In more general terms, the fact that a relatively simple modification of the length and demarcation of the dorsal dermal papilla is correlated with a more intricate architecture and a modified final shape of the cornified claw sheath (Siedamgrotzky, 1871) demonstrates how relatively small morphological changes within a complex organ can result in major overall changes in the structure and function of that organ.

The functional significance of the curved ledge not only reinforcing the medial and lateral sides of the cornified claw sheath but also ensuring an apical direction of horn production was not recognized by earlier authors, even though structures that can be interpreted as curved ledges have been depicted for isolated cornified claw sheaths of various mammals (see Boas 1931). As our study shows, an understanding of the formation and structure of the blade horn and its relationship to other horn segments of the cornified claw sheath is instrumental for understanding the mechanism of shedding superficial horn caps from cornified claw sheaths without damaging the underlying living epidermis and dermis.

The blade horn thickens and reinforces the lateral and medial side walls of the cornified claw sheath, with the effect that the cornified claw sheath is less likely to buckle when transverse forces are applied to it. Such forces are generated during prey capture, for example, when the digits of the front paw are first extended and spread apart and subsequently flexed while the paw is pulled back. The blade horn (with variable amounts of external coronary and proximal cone horn on its external surface, depending on the degree of wear that has taken place) also forms the cutting edges of the cornified claw sheath, which enable the claw to penetrate through the tough and pliable skin into the fibrous dermis of mammalian prey. This would not be possible with just the conical claw tip, just as a furrier's needle for hand-sewing leather and fur is fashioned with three sharp cutting edges in contrast to a tailor's sewing needle with its smooth and round surface.

\section{The claw-shedding mechanism}

Siedamgrotzky (1871) was apparently not aware that cats shed their claws, a fact that was described by De Weerdt (1927). Today at least, it is well known among veterinarians that cats and dogs shed their claws (B. Luikhart; staff at the Baton Rouge Zoo), although this is not discussed in the scientific literature. In the following, the claw-shedding mechanism is described based on our detailed and integrated morphological observations. In order to facilitate comprehension of the complex interactions, references to relevant figures are included.

The capacity for shedding superficial layers of the cornified claw sheath in cats appears to be dependent on the development of microcracks within the surface layers of the cornified claw sheath as a result of internal strain due to growth processes and of bending stresses in the course of normal use of the claws. Such microcracks are visible on the surface of the external coronary horn as it emerges from underneath the unguicular pleat (Fig. 6a). They parallel not only the proximal edges of a shed horn cap (Figs $6 a, 14 b$ ) but also the distalmost among the 
radial ridges that are formed at the levels of the dermoepidermal interface and the interface between the living and cornified epidermis (Figs $8 a, b, 9 b, 10 a, b, 11 a$ ) of the proximal cone and parietal epidermis. This particular unevenness in the thickness of the tissue underlying the cornified claw sheath may be the result of stresses within the dermis and epidermis as a result of the accelerated growth rate of the apical cone epidermis on the dorsal side of the cone epidermis as compared with that of the proximal cone epidermis on the proximo-palmar side of the cone epidermis due to the different sizes of the areas covered by the horn-generating living cone epidermis (Fig. 7).

The microcracks in the superficial coronary horn, in contrast, are likely the result of bending stresses that have occurred in the course of the normal use of the claws for climbing or prey catching. During these activities, large tensile forces are exerted on the tip of the cornified claw sheath. In reaction, the curvature along the dorsal side of the cornified claw sheath tends to be stretched and lessened, and the medial and lateral sides tend to straighten and move closer together. When the tensile forces on the cornified claw sheath are released, the resilience of the horn material and underlying soft tissues (i.e. living epidermis and dermis) return the cornified claw sheath to its curved resting conformation. On the lateral and medial sides of the cornified claw sheath, the bending stresses during these kinds of deformations are likely to be concentrated at the border between the free part of the side walls and the part that is stabilized and encased within the unguicular recess proximal to the unguicular pleat. Indeed, microcracks on the free surface of the medial and lateral sides of the cornified claw sheath are concentrated near the distal rim of the unguicular pleat (Fig. 6a). The microcracks that develop as a result of the bending stresses on the dorsal curvature of the cornified claw sheath appear farther apically where the cornified claw sheath consists of solid horn material (Figs 6, 7, 14b).

After the appearance of a microcrack through the superficial horn layer, the coronary horn will continue to be pushed apically by the proliferating living epidermis within the unguicular recess and by the proliferating living epidermis on the slanted face of the curved ledge. As a result, the microcrack will widen into a gap, thereby exposing the underlying horn surface, in which a new crack will eventually develop. The appearance of microcracks while the horn of the cornified claw sheath continues to be pushed apically results in a succession of microcracks along the proximal edge of the developing apical horn cap, which is eventually shed (Figs 6, 14b). Along the dorsal curvature, this staggering of microcracks is less obvious because the microcracks appear here mostly parallel to the growth direction of the horn (Fig. 14b).

At the same time as the developing cap of superficial coronary horn is pushed apically, it is also continuously pushed outwards by the underlying proliferating living epidermis, which generates the parietal horn. As a result, the developing apical cap of superficial horn appears to be more superficial than the superficial coronary horn emerging from underneath the distal rim of the unguicular pleat (Fig. 10c).

The microcracks expose edges of horn layers to water loss. In combination with aging and continuing internal strain throughout the cornified claw sheath, these processes promote the formation of intercellular cracks that propagate from the peripheral microcracks through the horn preferentially along the interfaces between the cornified cell layers. In this manner, the separation of superficial layers can proceed tangentially to the interface between the living tissues and the cornified epidermis without creating perpendicular cracks that would damage the underlying living tissues. Hence, the ongoing simultaneous horn production and formation of microcracks result in superficial layers of coronary horn being separated from underlying layers of coronary horn through tangential cracks that propagate through the horn material starting from the superficial microcracks. As can be seen from the surface structure of shed horn caps, several microcracks may appear before a particular microcrack spreads between two layers of horn and separates a horn cap from the main part of the cornified claw sheath in preparation for the shedding of the horn cap. The actual removal of this horn cap is probably facilitated by the characteristic scratching behavior of cats on rough surfaces of bark or textile.

The selective regime for the evolution of the clawshedding mechanism in cats is likely to be connected with the need to maintain sharp cutting edges and a sharply pointed tip, as well as to be able to free the claws from struggling prey or other substrates without the risk of pulling the entire claw sheath off the vascularized and innervated dermal claw bed. At this point in time, it is less clear why small dogs and even horses have evolved the capacity for shedding their claws or hooves, respectively. It may be hypothesized that the shedding of superficial horn layers of claws and hooves is more widespread among terrestrial vertebrates than hitherto assumed and that, therefore, the shedding mechanism of cats is only more pronounced and effective because it has evolved under the selective regime for climbing and prey catching. Additional studies will be needed to clarify these and other questions concerning the evolutionary history of cornified digital end organs.

\section{Acknowledgements}

We would like to thank Dr Jean-Yves Sire (CNRS, Université Paris 6) and Dr Matt Vickaryous (University of Guelph) for their invitation to contribute this report to the special issue. Dr Sybille Ernsberger prepared the histological slides (see Fig. 4). Dr William G. Henk [Department of Comparative Biomedical Sciences, Louisiana State University (LSU)] was instrumental in assisting with 
the production of the SEM pictures (see Figs 5, 6, 7 and 13). Dr Daniel J. Hillmann and Cathryn Sparks (Department of Comparative Biomedical Sciences, LSU) were instrumental in providing the specimens. Dr Barbara Luikhart (Galvez Veterinary Clinic, Prairieville, Louisiana, USA) and the staff at the Baton Rouge Zoo provided information on the shedding of claws in dogs and large cats. Ben Dubansky and Will and Morgan Owens provided specimens of shed claws from Dachshund and Chihuahua mutts (i.e. hybrid dogs). Dr Clinton S. Willson (Department of Civil and Environmental Engineering, LSU) collected the phase-contrast enhanced synchrotron x-ray computed tomography data at the GeoSoilEnviroCARS Sector 13 (Advanced Photon Source at Argonne National Laboratory, University of Chicago, Chicago, IL, USA). GeoSoilEnviroCARS is supported by the National Science Foundation (EAR-0622171) and Department of Energy (DE-FG02-94ER14466). The SkyScan 1074 was provided by Erno Sajo (Department of Physics \& Astronomy, LSU) through an LSU Student Technology Fee grant. The research was supported by an LSU Foundation account for morphological research to D.G.H.; by a much appreciated LSU Interdisciplinary Faculty Research Grant to D.G.H., L.G.B., Richard L. Kurtz (Department of Physics \& Astronomy, LSU), Randy R. Price (Department of Biological and Agricultural Engineering, LSU) and Clinton S. Willson (Department of Civil and Environmental Engineering, LSU); by a contract from the U.S. Department of Energy (DE-AC02-06CH11357) to Clinton S. Willson; and by a National Science Foundation grant (NSF CHE-0517236) to L.G.B. Dr Rustin Moore (Department of Veterinary Clinical Sciences, LSU) generously gave of his time to assist in the preparation of the proposal for the LSU Interdisciplinary Faculty Research Grant. Mary Sanders-East and Sigrid N. Hamilton assisted in the preparation of the manuscript.

\section{References}

Al-Bagdadi F (1993) The integument. In Miller's Anatomy of the Dog, 3rd edn (ed. Evans H), pp. 98-121. Philadelphia, Pennsylvania: W. B. Saunders Company.

Banks WJ (1986) Applied Veterinary Histology. Baltimore, Maryland: Williams \& Wilkins.

Boas JEV (1931) Krallen (inkl. Nägel, Hufe, Klauen). In Handbuch der vergleichenden Anatomie der Wirbeltiere, Vol. 1 (eds Bolk L, Göppert E, Kallius E, Lubosch W), pp. 521-544. Berlin: Urban \& Schwarzenberg. Reprinted: Amsterdam: A. Asher \& Co.

Bragulla H, Ernsberger S, Budras K-D (2001) On the development of the papillary body of the feline claw. Anat Histol Embryol 30, 211-217.

Bragulla HH, Homberger DG (2007) The role of the specific, profilaggrin-containing keratohyalin granules in the developing epidermis of the fetal horse hoof. Pferdeheilkunde 23, 5-20.

Bragulla HH, Homberger DG (2009) Structure and functions of keratin proteins in simple, stratified, keratinized and cornified epithelia - a review. J Anat 214, 516-559.
Bryant HN, Russell AP, Laroiya R, Powell GL (1996) Claw retraction and protraction in the Carnivora: Skeletal microvariation in the phalanges of the Felidae. J Morphol 229, 289-308.

De Weerdt ON (1927) Do cats sharpen their claws? Science N.S. 66 398-399.

Dyce KM, Sack WO, Wensing CJG (2002) Textbook of Veterinary Anatomy, 3rd edn. Philadelphia, Pennsylvania: W. B. Saunders Company.

Ernsberger S (1998) Zur Ontogenese der Katzenkralle. Doctoral Dissertation, Institut für Veterinär-Anatomie, Fachbereich Veterinärmedizin, Freie Universität, Berlin, Germany.

Gonyea W, Ashworth A (1975) The form and function of retractile claws in the Felidae and other representative carnivorans. $J$ Morphol 145, 229-238.

Habermehl K-H (1981) Skin and cutaneous organs. In The Anatomy of the Domestic Animals, Vol. 3 (eds Nickel R, Schummer A, Seiferle E), pp. 441-557. Berlin: Verlag Paul Parey.

Ham K, Barnett HA, Ogunbakin T, Homberger DG, Bragulla $\mathbf{H H}$, Matthews II KL, Willson CS, Butler LG (2006) Imaging tissue structures: Assessment of absorption and phase-contrast X-ray tomography imaging at 2-nd and 3-rd generation synchrotrons. Proc SPIE 6318, 631822, 1-10.

Hamrick MW (2001) Development and evolution of the mammalian limb: adaptive diversification of nails, hooves, and claws. Evol Dev 3, 355-363.

Hamrick MW (2003) Evolution and development of mammalian limb integumentary structures. J Exp Zool (Mol Dev Evol) 298B, 152-163.

Homberger DG (2001) The case of the cockatoo bill, horse hoof, rhinoceros horn, whale baleen, and turkey beard: The integument as a model system to explore the concepts of homology and non-homology. In Vertebrate Functional Morphology: Horizon of Research in the 21st Century (eds Dutta HM, Datta Munshi JS), pp. 317-343. Enfield, New Hampshire: Science Publishers Inc.

Homberger DG, Brush AH (1986) Functional morphological and biochemical correlations of the keratinized structures of the African Grey Parrot (Psittacus erithacus L.). Zoomorphology 106, 103-114.

Maddin HC, Eckhart L, Jaeger K, Russell AP, Ghannadan M (2009) The anatomy and development of the claws of Xenopus laevis (Lissamphibia: Anura) reveal alternate pathways of structural evolution in the integument of tetrapods. J Anat 214, 607-620.

Siedamgrotzky O (1871) Ueber die Structur und das Wachsthum der Hornscheiden der Wiederkäuer und der Fleischfresser. Dresden: G. Schönfeld's Verlagsbuchhandlung (C. A. Werner).

Starck D (1982) Integument und Anhangsorgane. In Vergleichende Anatomie der Wirbeltiere auf evolutionsbiologischer Grundlage, Vol. 3, pp. 131-257. Berlin: Springer-Verlag.

Vollmerhaus B, Roos H (2000) Die Kralle der Hauskatze (Felis catus) - eine Formenanalyse. Anat Histol Embryol 29, 193-195. 